\title{
Taphonomy and taxonomy of a juvenile lambeosaurine (Ornithischia: Hadrosauridae) bonebed from the late Campanian Wapiti Formation of northwestern Alberta, Canada
}

\author{
Brayden Holland ${ }^{\text {Corresp., } 1}{ }^{\text {, Phil R Bell }}{ }^{1}$, Federico Fanti ${ }^{2}$, Samantha Hamilton ${ }^{3}$, Derek W Larson ${ }^{4}$, Robin Sissons ${ }^{3}$, \\ Corwin Sullivan ${ }^{3,4}{ }^{\text {, Matthew J Vavrek }}{ }^{5}$, Yanyin Wang ${ }^{3}$, Nicolás E Campione ${ }^{\text {Corresp. } 1}$ \\ ${ }^{1}$ Palaeoscience Research Centre, School of Environmental and Rural Science, University of New England, Armidale, New South Wales, Armidale \\ 2 Dipartimento di Scienze Biologiche, Geologiche e Ambientali, Alma Mater Studiorum, Università di Bologna, Bologna, Italy \\ 3 Department of Biological Sciences, University of Alberta, Edmonton, Alberta, Canada \\ 4 Philip J. Currie Dinosaur Museum, Wembley, Alberta, Canada \\ 5 Department of Natural History, Royal Ontario Museum, Toronto, Ontario, Canada \\ Corresponding Authors: Brayden Holland, Nicolás E Campione \\ Email address: blongle2@myune.edu.au, ncampion@une.edu.au
}

Hadrosaurid (duck-billed) dinosaur bonebeds are exceedingly prevalent in upper Cretaceous (Campanian-Maastrichtian) strata from the Midwest of North America (especially Alberta, Canada, and Montana, U.S.A) but are less frequently documented from more northern regions. The Wapiti Formation (Campanian-Maastrichtian) of northwestern Alberta is a largely untapped resource of terrestrial palaeontological information missing from southern Alberta due to the deposition of the marine Bearpaw Formation. In 2018, the Boreal Alberta Dinosaur Project rediscovered the Spring Creek Bonebed, which had been lost since 2002, along the northern bank of the Wapiti River, southwest of Grande Prairie. Earlier excavations and observations of the Spring Creek Bonebed suggested that the site yielded young hadrosaurines. Continued work in 2018 and 2019 recovered $\sim 300$ specimens that included a minimum of eight individuals, based on the number of right humeri. The morphology of several recovered cranial elements unequivocally supports lambeosaurine affinities, making the Spring Creek sample the first documented occurrence of lambeosaurines in the Wapiti Formation. The overall size range and histology of the bones found at the site indicate that these animals were uniformly late juveniles, suggesting that age segregation was a life history strategy among hadrosaurids. Given the considerable size attained by the Spring Creek lambeosaurines, they were probably segregated from the breeding population during nesting or caring for young, rather than due to different diet and locomotory requirements. Dynamic aspects of life history, such as age segregation, may well have contributed to the highly diverse and cosmopolitan nature of Late Cretaceous hadrosaurids. 


\section{Taphonomy and taxonomy of juvenile lambeosaurine}

\section{2 (Ornithischia: Hadrosauridae) bonebed from the late Campanian}

3 Wapiti Formation of northwestern Alberta, Canada

4

5 Brayden Holland ${ }^{1}$, Phil R. Bell ${ }^{1}$, Federico Fanti ${ }^{2}$, Samantha M. Hamilton ${ }^{3}$, Derek W. Larson ${ }^{4}$,

6 Robin L. Sissons 3 , Corwin Sullivan ${ }^{3,4}$, Matthew J. Vavrek 5 , Yan-Yin Wang ${ }^{3}$, Nicolás E.

7 Campione $^{1}$

8

$9 \quad{ }^{1}$ Palaeoscience Research Centre, School of Environmental and Rural Science, University of New

England, Armidale, NSW, Australia

$11{ }^{2}$ Dipartimento di Scienze Biologiche, Geologiche e Ambientali, Alma Mater Studiorum,

12 Università di Bologna, Bologna, Italy

13

${ }^{3}$ Department of Biological Sciences, University of Alberta, Edmonton, AB, Canada

${ }^{4}$ Philip J. Currie Dinosaur Museum, Wembley, AB, Canada

${ }^{5}$ Department of Natural History, Royal Ontario Museum, Toronto, ON, Canada

16

17 Corresponding Authors: 
19 University of New England, Armidale, NSW, 2351, Australia

20 Email address: blongle2@myune.edu.au; ncampion@une.edu.au

21 Abstract

22 Hadrosaurid (duck-billed) dinosaur bonebeds are exceedingly prevalent in upper Cretaceous

23 (Campanian-Maastrichtian) strata from the Midwest of North America (especially Alberta,

24 Canada, and Montana, U.S.A) but are less frequently documented from more northern regions.

25 The Wapiti Formation (Campanian-Maastrichtian) of northwestern Alberta is a largely untapped

26 resource of terrestrial palaeontological information missing from southern Alberta due to the

27 deposition of the marine Bearpaw Formation. In 2018, the Boreal Alberta Dinosaur Project

28 rediscovered the Spring Creek Bonebed, which had been lost since 2002, along the northern bank of the Wapiti River, southwest of Grande Prairie. Earlier excavations and observations of the Spring Creek Bonebed suggested that the site yielded young hadrosaurines. Continued work in 2018 and 2019 recovered $\sim 300$ specimens that included a minimum of eight individuals, based on the number of right humeri. The morphology of several recovered cranial elements unequivocally supports lambeosaurine affinities, making the Spring Creek sample the first documented occurrence of lambeosaurines in the Wapiti Formation. The overall size range and histology of the bones found at the site indicate that these animals were uniformly late juveniles, suggesting that age segregation was a life history strategy among hadrosaurids. Given the considerable size attained by the Spring Creek lambeosaurines, they were probably segregated from the breeding population during nesting or caring for young, rather than due to different diet and locomotory requirements. Dynamic aspects of life history, such as age segregation, may well have contributed to the highly diverse and cosmopolitan nature of Late Cretaceous hadrosaurids. 


\section{Introduction}

42

Macrofossil bonebeds are a source of palaeontological data that greatly contribute to our understanding of anatomy, diversity, life history, community structure, behaviour, population dynamics, and taphonomy (Rogers et al., 2007). In North America, hadrosaurid dinosaur bonebeds are particularly concentrated in uppermost Cretaceous (Campanian-Maastrichtian) deposits, notably in those of the Belly River and Edmonton groups in southern Alberta, Canada (Getty et al., 1998; Eberth \& Getty, 2005; Eberth \& Currie, 2010; Bell \& Campione, 2014; Eberth, 2015; Evans et al., 2015) and the Two Medicine, Hell Creek, Lance, and Judith River formations in the northern part of the western United States (Christians, 1992; Varricchio \& Horner, 1993; Britt et al., 2009; Scherzer \& Varricchio, 2010; Keenan \& Scannella, 2014; PrietoMárquez \& Gutarra, 2016). Hadrosaurid specimens from bonebeds in these formations were among the first dinosaurs to be histologically sampled, which allowed for the reconstruction of their growth rates (Horner \& Currie, 1994; Horner et al., 1999, 2000) and provided the first evidence for parental care in dinosaurs (Horner \& Makela, 1979; Horner et al., 2000). Despite their frequency and importance, large numbers of North American hadrosaurid bonebeds have not been described in detail, particularly in northern rock units such as the Wapiti Formation (Fanti \& Catuneanu, 2009; Fanti \& Miyashita, 2009). These offer the opportunity to explore the diversity and preservation of hadrosaurids outside the traditionally sampled North American strata.

In northwestern Alberta, Wapiti Formation deposits span the mid-Campanian to upper Maastrichtian and are contemporaneous with most of the Belly River and Edmonton groups in southern Alberta (Fanti \& Catuneanu, 2009; Eberth \& Braman, 2012). Unlike its more famous southern counterparts, which are interrupted by marine transgressions of the Bearpaw Formation, 
64 the Wapiti Formation is a continuous package of terrestrial sediments (Eberth \& Getty, 2005;

65 Fanti \& Catuneanu, 2009; Eberth \& Braman, 2012). Although the Wapiti Formation was

66

67

68

originally well-known only for a single ceratopsian site, the Pipestone Creek Bonebed (Currie et al., 2008a), fieldwork over the past 10-15 years has uncovered abundant vertebrate ichnofossils (Bell et al., 2013; Fanti et al., 2013), articulated skeletons with skin impressions (Bell et al., 2014a; Bell et al., 2014b), microfossil sites (Fanti \& Miyashita, 2009), and macrofossil bonebeds (Tanke, 2004; Currie et al., 2008a; Fanti et al., 2015) (Fig. 1).

The Pipestone Creek Bonebed was discovered in 1974 (Tanke, 2004) and has produced disarticulated bones representing at least 27 juvenile- to adult-sized individuals of the ceratopsian Pachyrhinosaurus lakustai, along with remains of the dromaeosaurid Boreonykus certekorum, tyrannosaurids, and non-dinosaurian vertebrates (Currie et al., 2008a; Bell \& Currie, 2016). Its unique faunal content has been used to support dinosaur endemism hypotheses across Laramidia during the Late Cretaceous (Currie et al., 2008a; Sampson et al., 2010; Lucas et al., 2016). The Wapiti River Bonebed, a second ceratopsian bonebed located west of the Pipestone Creek Bonebed, is dominated by Pachyrhinosaurus specimens that have not yet been conclusively identified at the species level. Notably, this bonebed represents one of the most inland occurrences of centrosaurine ceratopsians in North America, given its inferred location relative to the Western Interior Seaway (Fanti et al., 2015). In addition to macrofossil bonebeds (defined as $>75 \%$ of specimens with a preserved length $>5 \mathrm{~cm}$; sensu Eberth et al., 2007a), the Kleskun Hill microfossil site (defined as $>75 \%$ of specimens with a preserved length $<5 \mathrm{~cm}$ ) preserves a high diversity of vertebrates, including fish, lizards, dinosaurs, and mammals (Fanti \& Miyashita, 2009). Several additional monodominant hadrosaurid bonebeds have subsequently 
86 been discovered, although not yet documented in detail (Tanke, 2004; Bell et al., 2014a; Bell et 87 al., 2014b).

88

89

90

91

92

The hadrosaurids of the Wapiti Formation are taxonomically enigmatic. Edmontosaurus regalis is currently the only species reported from this temporally extensive formation (Bell et al., 2014a; Bell et al., 2014b). The majority of hadrosaurid material so far recovered came from Unit 4 of the formation, which is broadly contemporaneous with portions of the Horseshoe Canyon Formation of southern Alberta, from which E. regalis is commonly recovered (Bell et al., 2014a; Bell et al., 2014b; Campione \& Evans, 2011; Eberth et al., 2013). Moreover, there is yet to be any definitive evidence to suggest the presence of another hadrosaurid taxon beside $E$. regalis in Unit 4 . However, it is unlikely that E. regalis was the only hadrosaurid from the entire formation, given the known diversity of hadrosaurids elsewhere in Alberta and the temporal extent of the Wapiti Formation. For instance, lambeosaurines have yet to be documented from the formation, despite their ubiquity within both the Belly River and Edmonton groups (Lull \& Wright, 1942; Evans et al., 2005; Ryan \& Evans, 2005; Evans \& Reisz, 2007; Evans et al., 2007; Evans, 2010; Brink et al., 2011; Mallon et al., 2012; Eberth et al., 2013; Farke et al., 2013). In 1988, Grande Prairie Regional College staff discovered several well-preserved hadrosaurid bones along the northern bank of the Wapiti River, approximately $150 \mathrm{~m}$ downstream of the confluence with the Spring Creek (Tanke, 2004). The site was dubbed the Spring Creek Bonebed (SCBB), and the material was suggested to possibly pertain to Hadrosaurinae, based on the "low deltoid crests" morphology seen in the recovered humeri. Given their size range, the bones were interpreted as the remains of subadult individuals that may have formed a "bachelor herd" (Tanke, 2004). Initial excavations at the SCBB undertaken by Grande Prairie Regional College and Royal Tyrrell Museum began in 1988, resulting in 40 
109 specimens recovered between 1988 and 2002. By 2003, however, the site had been obscured by

110 riverbank slumping (Tanke, 2004) and could not be rediscovered despite repeated attempts over

111 the following years. The bonebed was finally rediscovered in 2018 by one of us (MJV) as part of

112 the Boreal Alberta Dinosaur Project and subsequently excavated during the 2018 and 2019 field

113 seasons (Fig. 2). These recent excavations secured hundreds of new hadrosaurid specimens,

114 including the first diagnostic cranial material.

In this study, we describe the anatomy of the most taxonomically informative hadrosaurid

116 bones preserved at the SCBB and examine the taphonomic factors that may have formed the

117 bonebed. We test the original suggestion that the material might belong to Hadrosaurinae

118 (Tanke, 2004) using a larger sample that encompasses more diagnostic elements and use

119 histological analyses to assess the age distribution of the bonebed sample. Finally, we consider

120 the nature of fossil deposition at the SCBB, with a particular focus on whether the bonebed

121 assemblage originated through attrition or mass mortality, and explore the implications for how

122 hadrosaurid life histories should be envisaged.

\section{Geological setting}

northwestern Alberta (Fig. 1) and into the eastern-most regions of British Columbia.

127 Stratigraphically, the Wapiti Formation overlies the marine Puskwaskau Formation and underlies

128 the terrestrial Scollard Formation (Fanti \& Catuneanu, 2009). Spanning from the mid-Campanian

129 ( 79.1 Ma) into the Maastrichtian ( 67 Ma), the Wapiti Formation is roughly contemporaneous

130 with the Belly River and Edmonton groups of southern Alberta and the Two Medicine and St. 
131 Mary River formations of northwestern Montana (Fanti \& Catuneanu, 2010; Eberth \& Kamo,

132 2020; Zubalich et al., 2021). The formation is subdivided into five units that suggest an overall

133 progression from channel-fill sandstones to floodplain-derived finer sediments (Fanti \&

134 Catuneanu, 2009, 2010). Importantly, coals from Unit 3 and the Red Willow coal zone (upper

135 Unit 4) are interpreted as synchronous with the maximum flooding surfaces of the marine

136 Bearpaw Formation and Drumheller Marine Tongue, respectively (Fanti \& Catuneanu, 2009).

137 However, actual marine sediments do not interrupt the succession of terrestrial strata in this

138 region, as they do in southern Alberta. Therefore, the Wapiti Formation represents a nearly

139 continuous mid-Campanian-Maastrichtian terrestrial record that is important for tracking faunal

140 transformation in northern Laramidia, particularly when marine transgressions inundated

141 southern Alberta.

Because the Wapiti Formation exposures in which the SCBB is located are highly

143 unstable and prone to slumping, the stratigraphic position of the bonebed is limited to within a

144 few metres. The SCBB is located $\sim 11.5 \mathrm{~km}$ downstream of the Pipestone Creek Bonebed,

145 placing it within Unit 3 of the Wapiti Formation and implying rough contemporaneity with the

146 lowermost units of the Horseshoe Canyon Formation (the Strathmore and Drumheller members:

147 Currie et al., 2008b; Eberth \& Braman, 2012; Zubalich et al., 2021). Unit 3 comprises channel

148 sandstones overlain by interbedded mudstones and siltstones, minor sandstone sheets, and

149 extensive coals, representing fluvial point bars within high-sinuosity fluvial systems in

150 floodplain environments (Fanti \& Catuneanu, 2009). At the SCBB locality (Fig. 3),

151 approximately 14 vertical metres of the Wapiti Formation are exposed on a cut bank of the

152 Wapiti River, where slumping has obscured some sedimentary features and the boundaries

153 between horizons. Nevertheless, massive mudstones up to $5.5 \mathrm{~m}$ thick (interrupted by thin sandy 
154 layers) dominate the exposure, alternating with sandstones up to $2.8 \mathrm{~m}$ thick (Fig. 3). The SCBB

155 is confined to a $\sim 40 \mathrm{~cm}$ thick horizon within the middle of a massive, organic-rich mudstone

156 approximately $3.7 \mathrm{~m}$ thick. Bones exhibit no signs of grading, range from 10 to $640 \mathrm{~mm}$ in

157 maximum length, and have no distinct preferred orientation (see Results). In addition to bones,

158 coalified plant remains $(<10 \mathrm{~cm}$ long), clay nodules, and amber $(<2 \mathrm{~cm}$ long $)$ are also present in

159 the bonebed. Conformably underlying the bonebed-hosting mudstone is a $\sim 80 \mathrm{~cm}$ thick

160 sandstone with shallow crossbedding, which overlies a coal layer that is only exposed during low

161 water periods. The overall sedimentary evidence indicates the SCBB was deposited on a

162 vegetated floodplain traversed by the meandering rivers that were the main depositional

163 environment for Unit 3 (Fanti \& Catuneanu, 2009).

164

165 Materials \& Methods

166 Excavation

167 Specimens collected by the Grande Prairie Regional College in 1988 and 1991 were

168 mapped but could not be placed in our quarry maps or used in our quarry analyses because

169 accompanying orientation data, field identifications, and field numbers were not recorded.

170 During the Boreal Alberta Dinosaur Project excavations in 2018 and 2019, orientation, plunge,

171 and maximum preserved length were recorded on-site for all specimens with a length:width ratio

$172 \geq 2$. Obvious taphonomic artefacts, such as fracturing, were noted. All specimens with a total

173 length $>5 \mathrm{~cm}$ were mapped by hand in $1 \times 1 \mathrm{~m}$ grids, subdivided into $10 \times 10 \mathrm{~cm}$ squares.

174 Specimens collected in 1988 and 1991 are accessioned at the Royal Tyrrell Museum of

175 Palaeontology (TMP), Drumheller, Alberta, Canada (TMP1988.094 and TMP1991.137 series), 
176 whereas specimens collected in 2018 and 2019 are accessioned in the collections of the

177 University of Alberta's Laboratory for Vertebrate Palaeontology (UALVP), Edmonton, Alberta, 178 Canada.

Histology

For consistency, we followed the methods and definitions used in previous histological studies of hadrosaurids (Horner et al., 1999; Horner et al., 2000; Vanderven et al., 2014; Woodward et al., 2015, Wosik et al., 2020). We sectioned the eight most complete humeri along the diaphysis (distal to the deltopectoral crest), as they offer the best sampled and most readily prepared bone from the bonebed (Fig. 4; Table 1). Humeri were chosen because they form the basis for MNI, guaranteeing that histological comparisons are performed on distinct individuals and approximating the relative age in the assemblage. Although humeri have been used in multiple hadrosaurid histological analyses (Horner et al., 2000; Vanderven et al., 2014; Wosik et al., 2020), future studies could sample yet-to-be-prepared tibiae and femora, to better constrain the absolute ages of these hadrosaurids (Horner et al., 1999; Horner et al., 2000; Vanderven et al., 2014; Woodward et al., 2015, Wosik, et al., 2020). (Australia), and thin sections of UALVP specimens were produced at the University of Alberta (Canada). Humeri sectioned at the University of New England were partially encased in epoxy resin to minimize damage during sectioning. The sections were cut using a diamond saw, before being mounted on slides and hand-polished with 600 grit silicon carbide. Slides were then placed 197 into a Petrothin thin sectioning machine and ground down to $200 \mu \mathrm{m}$. The slides were then 
198 placed into a Logitech LP50 polisher to be ground down to $30 \mu \mathrm{m}$. Sections were analyzed under

199 10X magnification on a Leica DM500 compound microscope and were photographed under LED

200 lighting with a Canon EOS 5DS.

201

Humeri prepared at the University of Alberta were sectioned at mid-diaphysis using a

202 table saw. Sections were then placed into plastic containers before being covered by EAGER

203 Polymers' EP4101UV Crystal Clear Polyester Resin (Castolite AP \& Castolite AC) and EP4920

204 MEK-P Castolite Hardener (mixed in a 1 oz: 10 drops volume ratio). The cured resin blocks

205 were cut in half using a table saw and mounted on plexiglass slides. Prior to mounting, both the

206 plexiglass slides and resin blocks were faced using 1000 grit silicon carbide grinding mixture.

207 The sections were then ground down on a Hillquist saw using 600 and 1000 grit grinding

208 mixtures until suitable transparency, rather than any predefined thickness, was achieved. Images

209 were captured under 4X magnification using a Nikon DS-FI3 camera, mounted on a Nikon

210 Eclipse E600 POL microscope, and Nikon NIS Elements (v. 4.60) imaging software housed in

211 the Caldwell Lab, University of Alberta.

212

213 Taphonomy

214 All specimens were identified and inspected for taphonomic and preparation artefacts following

215 laboratory preparation. Taphonomic analyses follow the procedures outlined by Behrensmeyer

216 (1991) and built upon by Eberth et al. (2007a) and Blob and Badgley (2007). Taphonomic

217 parameters were broadly categorized into either assemblage, quarry, or bone modification data,

218 and analyzed under subcategories as outlined by Behrensmeyer (1991). In this study, a specimen

219 is defined as a vertebrate hard part (e.g., bone, tooth, scale) regardless of possible association 
220 with another bone (Blob \& Badgley, 2007). Accordingly, multiple fused bones represent a single

221 specimen, whereas unfused, but associated, bones (e.g., a string of vertebrae) are counted

222 individually as distinct specimens. An element is defined as a vertebrate hard part in its entirety,

223 such as a complete tibia as opposed to a distal piece of a tibia (Badgley, 1986; Blob \& Badgley,

224 2007). A broken, but matchable element (e.g. a femur broken into four pieces, or distal and

225 proximal ends of a femur) is regarded as a single specimen if the pieces can be reassembled.

226 Analyses of taphonomic data utilized the total number of specimens $(\mathrm{N})$, the number of

227 identifiable specimens (NISP), and the number of prepared specimens (NPSP). The NISP is

228 larger than the NPSP because few prepared specimens could not be identified. Except where

229 noted, bone modification data are based on the NPSP, whereas assemblage and quarry data are

230 based on the NISP. The minimum number of individuals (MNI) was determined by counting the

231 most common unique skeletal elements (Blob \& Badgley, 2007), which in the case of the SCBB

232 were right humeri (Fig. 4; Table 1).

233

Voorhies (1969) groups are commonly used to assess skeletal representation and fluvial

234 influence in bonebeds (Gangloff \& Fiorillo, 2010; Bell \& Campione, 2014; Evans et al., 2015).

235 However, their application to large-bodied extinct taxa has been questioned (Eberth et al., 2007a;

236 Britt et al., 2009; Peterson et al., 2013), as Voorhies groups do not account for bone

237 completeness and disarticulation, particularly of the skull, prior to transportation. Additionally,

238 Voorhies groups were originally used to examine the taphonomy of skeletally fused mammals

239 rather than reptiles. Such factors can cause inaccurate element counts, leading to incorrect ratios

240 between Voorhies groups and false inferences regarding fluvial influence, but elements can be

241 counted more accurately by accounting for the lack of skeletal fusion in younger hadrosaurids

242 (Horner \& Currie, 1994). Moreover, the relative proportion of element representation is more 
243 informative than absolute counts (Gangloff \& Fiorillo, 2010; Bell \& Campione, 2014). For this

244 study, Voorhies groups are based on inferred susceptibility to transport given a specimen's size

245 (as redefined by Scherzer \& Varricchio, 2010; Varricchio, 1995), and the expected numbers of

246 each element in a single hadrosaurid skeleton were derived from Horner et al. (2004) and Bell

247 and Campione (2014) (Table 2).

248 Age class designation follows two criteria. The first is that of Horner (2000), who

249 identified six classes based on histology: early and late nestling, early and late juvenile, sub-

250 adult, and adult. When histological data are not available, we follow the size-based criterion used

251 by Evans (2010), in which individuals beyond perinatal size and yet to attain $50 \%$ of adult size

252 are defined as juvenile.

\section{Results}

255 Anatomical descriptions

256 The most diagnostic elements recovered from the SCBB include a premaxilla, maxilla, 257 and postorbital, all of which show unambiguous lambeosaurine affinities. These elements are 258 described in detail below.

Premaxilla-A partial left premaxilla (UALVP 60537) is preserved in two equal-length but non-contiguous pieces, separated by a gap of several millimetres (Fig. 5). Most of the anterior region of the premaxilla is intact, revealing the facial angle and the shape of the bill. contribution to the cranial crest. 

rhamphotheca in life (Morris, 1970; Horner et al., 2004; Farke et al., 2013). In dorsal view, the oral margin is transverse anteriorly and broadly arcuate more posteriorly with a smooth transition to the post-oral region of the premaxilla. As a result, it does not form a distinct, ventrolaterally directed tab-like process, as seen in other juvenile lambeosaurines (such as Hypacrosaurus, Parasaurolophus, and Velafrons coahuilensis; Gates et al., 2007; Evans, 2010; Brink et al., 2011), although the development of this process varies ontogenetically in lambeosaurines (Table 3; Evans, 2010). The anterior third of the preserved length of the premaxilla's dorsal surface is concave mediolaterally, corresponding to the contour of the bony naris. The preserved bony naris has a length:width ratio of 3.5 , exceeding the ratio observed in the southern Laramidian taxa Magnapaulia laticaudus and V. coahuilensis (1.85-2.85; Prieto-Márquez et al., 2012), though this is likely due to ontogeny (Prieto-Márquez et al., 2012). The bony naris attenuates anterior to the crest-snout angle, similar to juvenile Lambeosaurus lambei, V. coahuilensis and Hypacrosaurus altispinus (Lull \& Wright, 1942; Ostrom, 1961; Evans et al., 2005; Gates et al., 2007; Evans, 2010), but in contrast to the more posterior attenuated bony naris seen in juvenile Corythosaurus (Table 3; Evans et al., 2005; Evans, 2010).

The posterolateral process is missing, exposing part of the narial vestibule in lateral view. In lateral aspect, the posterodorsal process becomes more dorsally inclined posteriorly, in the region representing the anterior part of the base of the crest. As preserved, the posterolateral process suggests a crest-snout angle of $\sim 158^{\circ}$ (Table 3 ), which is closest to the angles mesasured from juvenile Parasaurolophus sp. (162; RAM 14000; Farke et al., 2013), V. coahuliensis (157% CPC-59; Gates et al., 2007), and H. altispinus (163; CMN 2247; Evans, 2010). 
287 from Corythosaurus casuarius: $116-155^{\circ}$, Hypacrosaurus stebingeri: $140^{\circ}-150^{\circ}$, and

288 Lambeosaurus sp. 62-156 (Evans et al., 2005; Evans, 2010; Brink et al., 2011, 2014).

Maxilla - The right maxilla (UALVP 59881b) retains the typical triangular body seen in

290

291

292

293

294

295

296

297

298

299

300

301

302

303

304

305

306

307

308

309

all hadrosaurids (Horner et al., 2004; Evans, 2010; Brink et al., 2011), despite lacking most of

the dorsal process and roughly half of the maxillary body anterior to the dorsal process (Fig. 6A).

The anterior fracture represents a dorsoventral shear revealing a cross-section of the most

anteriorly preserved maxillary tooth family, showing at least three replacement teeth enclosed

within the maxillary body (Fig. 6E). In dorsal view (Fig. 6C, D, and E), a shelf that would have

supported the posterolateral process of the premaxilla extends medially from the maxillary body

(Horner et al., 2004). Lateral to the medial shelf is a large dorsal foramen that opens along the anterodorsal margin of the dorsal process (Fig. 6C); the presence of a foramen at this location is characteristic of lambeosaurines (Horner et al., 2004). Lateral to the large dorsal foramen is a smaller foramen (Fig. 6C), as also seen in juvenile C. casuarius (ROM 759: Evans et al., 2005).

In the lateral aspect, the preserved portion of the dorsal process extends dorsally, forming an angle of $\sim 151^{\circ}$ with the anterodorsal edge of the maxillary body (Fig. 6A; Table 3). This angle is similar to that seen in juvenile C. casuarius (e.g., ROM 759) and L. lambei (e.g., ROM 758), as well as $V$. coahuilensis (Gates et al., 2007), but differs from the more obtuse angles seen in subadult H. stebingeri (TMP 1994.385.0001: Brink et al., 2011), juvenile H. altispinus (CMN 2247: Evans, 2010), and juvenile Parasaurolophus (RAM 14000: Farke et al., 2013). The lateral aspect of the dorsal process is mostly occupied by the sutural surface for the jugal, which is anteriorly delimited by a distinct, roughly arcuate ridge. The shape of the ridge indicates that the anterior process of the jugal was broadly rounded, as in most lambeosaurines (Lull \& Wright, 1942; Evans et al., 2005; Evans, 2010; Brink et al., 2011), rather than distinctly pointed as 
310 typically observed in hadrosaurines and Parasaurolophus (Horner, 1983, 1992; Prieto-Márquez

311 \& Norrell, 2010; Bell, 2011a; Prieto-Márquez, 2012; Xing et al., 2017).

The ectopterygoid ridge projects from the maxilla laterally at a level ventral to the contact

surface for the jugal and extends anteroposteriorly along the posterior two-thirds of the preserved

maxillary body. In the lateral aspect, the ridge is mostly parallel to the tooth row but is deflected

ventrally at the posterior end. In dorsal view and posterior to the dorsal process, the

the shelf forms a lip curving ventrally similar to Parasaurolophus sp. (RAM 14000: Farke et al.,

The ectopterygoid ridge partially covers the posteriormost foramen of a series of three foramina

the same general area in lambeosaurines, the specific number, shape, and position of these foramina are subject to individual and ontogenetic variation (Evans, 2010).

preserved length of the maxilla. The incomplete tooth row includes 23 identifiable tooth families, which alternate between one or two functional teeth on the occlusal surface (Fig. 6F). The number of functional teeth per tooth family ranges from one to three in hadrosaurids (Horner et al., 2004). view, typical for hadrosaurids (Lull \& Wright, 1942). Three major processes are preserved; the anterior process, anteroventrally oriented jugal process, and posteriorly oriented squamosal process. A smaller medial process is also preserved (Fig. 7). The postorbital has undergone evident diagenetic distortion, the dorsal and lateral surfaces having been flattened into one plane. 
333 In connection with this, there is a large depression on the dorsal surface of the anterior process

334 and a corresponding sinuous crack on the ventral surface, although such a crack may represent a 335 groove for nerves and blood vessels. sutural surface for the prefrontal along its anteromedial margin. There are no signs of doming at the prefrontal sutural surface (Table 3), unlike Kazaklambia convincens, where a prominent postorbital dome occurs on the dorsal surface of the bone (Bell and Brink, 2013). The prefrontal sutural surface terminates posteriorly at a small medial process, marking the separation between the prefrontal and the frontal sutural surfaces. Accordingly, the frontal was excluded from the orbital margin, as is typical for lambeosaurines (Horner et al., 2004). The medial process is dorsoventrally broad at its base and tapers medially, suggesting that it underlay the prefrontal and frontal contact and was thus not visible in dorsal view. Posterior to the medial process, the sutural surface for the frontal is less interdigitated than that for the prefrontal and bears a longitudinally oriented groove that opens dorsomedially. In dorsal view, the frontal sutural surface is distinctly concave, owing to the aforementioned medial process combined with a more posteriorly positioned one that would have extended medially to contact the parietal (Horner, 1992; Evans et al., 2005; Evans, 2010). The ventral margin of the anterior process of the postorbital and the anterior margin of the jugal process form the posterodorsal rim of the orbit. The orbital rim is slightly rugose and is not pierced by a foramen, present in Amurosaurus riabinini, Prosaurolophus maximus, and Maiasaura peeblesorum (Horner, 1983, 1992;

353 Godefroit et al., 2004). of the ventral end. The lateral surface of the jugal process is concave, as seen in the juvenile $C$. 
356

357

358

359

360

361

362

363

364

365

366

367

368

369

370

371

372

373

374

375

376

377 Histology

casuarius (AMNH 5461), and is broader anteroposteriorly than that of Parasaurolophus, though not to the extent seen in Edmontosaurus (Parks, 1922; Wiman, 1931; Ostrom, 1961, 1963;

Campione \& Evans, 2011). The medial surface of the jugal process bears a prominent dorsoventral ridge that bifurcates dorsomedially to form a V-shaped fossa for the dorsolateral process of the laterosphenoid. This fossa is typically hemispherical/semicircular in hadrosaurids [e.g., Prosaurolophus maximus (MOR 447 6.24.6.2), E. regalis (ROM 53513 and 53514), Brachylophosaurus canadensis (MOR 1071 6.30.89.4), and L. magnicristatus (Evans and Reisz, 2007).

The squamosal process is the longest of the main postorbital processes. The ventral margin of the process, which forms the dorsal rim of the infratemporal fenestra, is arcuate (Table 3), similar to that seen in juvenile H. stebingeri (TMP 1994.385.01; Brink et al., 2011) and C. casuarius (ROM 759; Evans et al., 2005), but unlike the straight margins seen in juvenile Parasaurolophus sp. (RAM 14000; Farke et al., 2013), K. convincens (PIN 2230/1; Bell and Brink 2013), and Lambeosaurus sp. (ROM 758; Brink et al., 2011). The squamosal process is also unlike the autapomorphic "dorsally positioned, high arching squamosal process" seen in $V$. coahuilensis (CPC-59; Gates et al., 2007). The posterior end of the process is lateromedially expanded, as in other lambeosaurines (Lull \& Wright, 1942; Farke et al., 2013), and bifurcated, as in all lambeosaurines except $H$. altispinus (Evans, 2010). The ventromedial surface of the squamosal process bears an anteroposteriorly oriented groove, and the area lateral to the groove is broader and more prominent than that medial to the groove. 
A general pattern of bone microstructure is present across the eight sampled humeri. The

379 humeri comprise a thick layer of cortical bone externally, and a core of trabecular bone

380 positioned at the centre of the diaphysis. No humeri exhibit a hollow medullary cavity. The

381 trabeculae consist of parallel-fibred bone, although the deepest part of the core of trabecular bone

382 is destroyed in most specimens due to diagenetic modification. External to the inner cancellous

383 bone, most sections show regions of dense Haversian systems that have replaced the primary

384 bone matrix (Fig. 8).

The outer half of the cortex comprises woven-fibred bone that ranges from plexiform to

reticulate, transitioning to laminar bone towards the periosteal surface. Open osteonal canals are

sporadically present on the periosteal surfaces of the humeri; we identified no external

fundamental systems. Resorption fronts are present in all sections. Regions of Haversian

reconstruction are restricted to the innermost layers and do not appear within the outer laminar

layer. Neither annuli nor lines of arrested growth (LAGs) were observed in any of the sections.

All aspects of bone microstructure indicate that skeletal growth was incomplete at the time of death.

Taphonomy

Assemblage data - A total of $\mathrm{N}=351$ vertebrate specimens were collected from the

SCBB, including partial and complete teeth, ossified tendons, and bones. The NISP is 273 , of which NPSP $=142$. Almost all $(99.7 \%)$ of the identifiable specimens are assigned to

Hadrosauridae, with only a single tyrannosaurid tooth as direct evidence of a second taxon within the bonebed, although toothmarks suggest other taxa were present before deposition. The 
400 three cranial elements described above can be referred to Lambeosaurinae. Based on the number

401 of right humeri collected (Fig. 4, Table 1), the current MNI of hadrosaurids is eight.

402 The maximum preserved lengths of individual specimens range from 10-640 mm (mean

$403=166 \mathrm{~mm}$; median $=136 \mathrm{~mm})$. Specimen lengths are positively skewed $($ skewness $=1.4918)$,

404 the vast majority of elements being $<400 \mathrm{~mm}$ in total length. Complete examples of each type of

405 element tend to be uniform in size, indicating the occurrence of a single growth stage, which is

406 supported by the histological results. Complete femora range from $558 \mathrm{~mm}$ to $640 \mathrm{~mm}$, placing

407 them in the late juvenile growth stage (sensu Horner et al. 2000). Total lengths of postcranial

408 elements, scaled against a complete Lambeosaurus sp. (AMNH 5340) skeleton (Farke et al.,

409 2013), suggest a total body length estimate of $\leq 4.3 \mathrm{~m}$ (Table 4$)$.

The vast majority of the bones were found disarticulated, with limited signs of

411 association. The only possible exception pertains to a dentary, a predentary, and a mass of

412 articulated teeth that were all found within an area $<0.5 \mathrm{~m}^{2}$ (Fig. 2). The representation of

413 Voorhies groups in the SCBB sample is more uniform than expected, given the juvenile

414 hadrosaurid skeleton structure (Table $2 ; \mathrm{X}^{2}=41.746$, $\mathrm{p}$-value $<<0.001$ ). In particular, there is a

415 significant underrepresentation of Voorhies group I relative to groups II and III.

$\mathrm{m}$, and the total excavation area was $35 \mathrm{~m}^{2}$ (Fig. 2). A femur recovered $\sim 15 \mathrm{~m}$ upstream from the

main excavation site, of similar size and preservation style to those recovered from the quarry,

420 to the bottom $40 \mathrm{~cm}$ of $\mathrm{a} \sim 2 \mathrm{~m}$ thick mudstone layer with no distinct grading of bioclasts.

421 Crevices (10-15 cm wide) found within the quarry walls suggest widespread slumping and the

422 possible displacement of the entire bonebed from its original position. The density of bones 
423 within each grid square ranges from 1 to 30 bones $/ \mathrm{m}^{2}$, with a mean of 7.5 bones $/ \mathrm{m}^{2}$. Preferential

424 alignment of long bones was difficult to determine from the SCBB as Rao's spacing test suggests

425 a significant departure from uniformity (test statistic $=183.6$; critical value $($ at $p=0.05)=$

426 143.8), whilst Kuiper's test of uniformity suggests a uniform distribution (test statistic $=1.05$;

427 critical value (at $\mathrm{p}=0.05)=1.7$ ). This inconsistency between tests may be related to the high

428 circular variance $\left(\sigma^{2}=0.93\right)$ caused by high bone orientation variability (Fig. 2$)$. Patchiness

429 indices $>1$ were recorded from both 2018 and 2019 excavations (1.67 and 1.35, respectively),

430 suggesting clumping of specimens rather than a random distribution.

Bone Modification-Of the prepared specimens from the SCBB, $44.2 \%$ are complete

432 (Table 5), ranging in size from small cranial elements to relatively large hindlimb elements. A

433 mixture of transverse post-burial fractures and perimortem spiral fractures represents the most

434 common fracture style, observed on $38.9 \%$ of the NPSP. Signs of abrasion are rare within the

435 SCBB, with only $13.9 \%$ of the NPSP showing low-level abrasion (stages 0 and 1 ) and $<2 \%$

436 exhibiting more severe levels (stages 2 and 3). Similarly, 89.7\% of NPSP show little to no

437 weathering (weathering stages $0-1$; Table 5, Fig. 4). The remaining $10.3 \%$ were observed to be

438 at weathering stage 2.

Biogenic modification of some bones in the sample can be inferred based on the presence

of parallel striae, which result from bone-substrate interactions and imply trampling

441 (Behrensmeyer et al., 1986). Approximately 33\% of the prepared specimens exhibit such striae.

442 The aforementioned perimortem spiral fractures are also consistent with trampling. Tooth marks

443 are present on $3.8 \%$ of NPSP and are represented by pits and conspicuous parallel score marks;

444 these marks primarily occur on limb bones. Given that the tooth marks are predominantly small,

445 U-shaped furrows (Fig. 9), it is likely that they were produced by small scavengers, potentially 
446 including small theropods (Bell \& Campione, 2014; Bell \& Currie, 2015). Some scavenging by

447 larger theropods may have occurred based on the presence of a single shed tyrannosaurid tooth

448 and toothmarks potentially left by smaller tyrannosaurid individuals. Finally, only a single

449 notable pathology is present on the supra-acetabular process of an incomplete ilium (UALVP

450 60540, Fig. 9). The pathology comprises a hemispherical erosion of the lateral surface of the

451 process, with smooth margins but an irregular and rugose internal surface.

\section{Discussion}

454 Systematics of the Spring Creek hadrosaurids Hadrosaurinae (or Saurolophinae, sensu Prieto-Márquez, 2010) based on the low deltopectoral crests observed on the humeri (Tanke, 2004). However, the prominence of the crest is known to vary ontogenetically, especially among lambeosaurines (Egi \& Weishampel, 2002; Horner et al., 2004), rendering this assignment questionable. The skull elements described in this study represent the first diagnostic cranial material from the SCBB and unequivocally support a lambeosaurine designation based on the following synapomorphies: external naris fully enclosed by the premaxilla, large oblate foramen opening dorsally on the anterodorsal margin of the maxilla, and jugal sutural surface on the maxilla with a broadly rounded anterior margin (Evans, 2010; Prieto-Márquez, 2010). Furthermore, the postorbital would have contacted the prefrontal, excluding the frontal from the orbital margin. This condition is typical of lambeosaurines, 466 despite being present in the hadrosaurines Prosaurolophus and Saurolophus (Horner, 1992; 467 Horner et al., 2004; Bell, 2011a, 2011b; McGarrity et al., 2013). The other specimens so far 
468 recovered from the SCBB are not diagnostic below Hadrosauridae. However, given their

469 consistent size and the absence of conspicuous variations that could indicate the presence of

470 multiple taxa, it is likely that all hadrosaurid specimens from the SCBB pertain to the same

471 species.

Unfortunately, the available sample of disarticulated juvenile elements provides limited

473 diagnostic information, making any taxonomic designation below Lambeosaurinae ambiguous.

474 The relatively acute angle between the body and dorsal process of the maxilla (Fig. 6) is more

475 consistent with that seen in C. casuarius and Lambeosaurus (Lull \& Wright, 1942; Evans et al.,

476 2005) than that seen in Hypacrosaurus and Parasaurolophus (Evans, 2010; Brink et al., 2011;

477 Farke et al., 2013). Similarly, the arched profile of the postorbital squamosal process is akin to

478 that in C. casuarius and L. magnicristatus (Evans \& Reisz, 2007). By contrast, the more

479 anteriorly attenuated bony naris of the premaxilla (Fig. 5) resembles that of $H$. altispinus and

480 Lambeosaurus (Lull \& Wright, 1942; Ostrom, 1961; Evans et al., 2005; Gates et al., 2007;

481 Evans, 2010; Brink et al., 2011), and the relatively obtuse snout-crest angle of the premaxilla is

482 most consistent with H. altispinus (Evans, 2010; Brink et al., 2014); but note that the postorbital

483 squamosal process (UALVP 59902; Fig. 7) differs from that of $H$. altispinus in being bifurcated

484 (Evans, 2010).

485

486

487

488

489

490
The SCBB lies within the upper strata of Unit 3 of the Wapiti Formation, which is roughly contemporaneous with the Bearpaw Formation and the Drumheller and Strathmore members of the lower Horseshoe Canyon Formation (Fig. 10). The SCBB lambeosaurines are, therefore, younger than known species of Corythosaurus, Lambeosaurus, and Parasaurolophus from the Dinosaur Park Formation and intermediate in age between $H$. stebingeri and $H$. altispinus from the Two Medicine and Horseshoe Canyon formations, respectively (Horner \& 
491 Currie, 1994; Brink et al., 2011; Mallon et al., 2012; Eberth \& Kamo, 2020). As a result, the

492 SCBB is apparently not contemporaneous with any other hadrosaurid species known from

493 Canada or the U.S.A. (Fig. 10), although it may be contemporaneous with the Mexican

494 lambeosaurines $V$. coahuilensis (Cerro del Pueblo Formation; Gates et al., 2007) and $M$.

495 laticaudatus (El Gallo Formation; Prieto-Márquez et al., 2012).

The SCBB is geographically located between the northernmost lambeosaurine in Alaska

497

498

499

500

501

502

503

504

505

506

507

508

509

510

511

512

513

(Takasaki et al., 2019) and those from southern Alberta (Fig. 10). Moreover, the SCBB is at a far higher paleolatitude than the contemporaneous Mexican lambeosaurine localities (Fig. 10). Faunal endemism was suggested for at least Unit 3 of the Wapiti Formation based on the occurrence of P. lakustai and B. certekorum, both of which are uniquely known from the Pipestone Creek Bonebed (Currie et al., 2008b; Bell \& Currie, 2016), although such endemism may be stratigraphic rather than biogeographic (Fowler, 2017). Additionally, the occurrence of E. regalis in Unit 4 may reflect a shift from endemism to dinosaur cosmopolitanism across Alberta (Bell et al., 2014a).

The fact that the SCBB specimens are geographically and/or stratigraphically isolated from all other documented lambeosaurine occurrences, combined with the potential rapid evolutionary turnover of lambeosaurines, as evinced from the Dinosaur Park Formation (Mallon et al., 2012), and the conflicting morphological signals described above, suggests that the lambeosaurine material from the SCBB may well represent a new species unique to the Wapiti Formation. Unfortunately, such a conclusion cannot be considered secure in the absence of more complete, especially more mature, cranial material that reveals a unique suite of character states. Irrespective of its precise taxonomic identification, the SCBB sample represents the first lambeosaurine material reported from the Wapiti Formation. The presence of a lambeosaurine in 
514 Unit 3 supports a similarity in overall faunal composition between portions of the Wapiti

515 Formation in northwestern Alberta to those from the southeast (Fanti \& Catuneanu, 2009;

516 Mallon et al., 2012; Eberth et al., 2013; Fanti et al., 2013; Fowler, 2017; Eberth \& Kamo, 2020).

517 Furthermore, this discovery supports the hypothesis that Late Cretaceous lambeosaurine

518 distributions extend into high-latitude regions, recently suggested based on an isolated

519 supraoccipital from the Prince Creek Formation of Alaska (Takasaki et al., 2019).

521 Taphonomy of the Spring Creek Bonebed

522 The SCBB is essentially monospecific, containing the remains of at least eight juvenile

523 lambeosaurines (thus far represented by 350 hadrosaurid bones) and one tyrannosaurid

524 (represented by a single shed tooth), which are inferred to have been buried in an organic-rich, 525 quiet-water setting based on the bonebeds mud-hosted facies. The tyrannosaurid tooth likely 526 entered the assemblage via scavenging rather than through the same event that caused the death

527 of the lambeosaurines, as non-dental tyrannosaurid material is yet to be recovered from the

528 bonebed. Furthermore, the light to minimal weathering (Table 5; Fig. 4) indicates that all the

529 bones remained exposed for about the same length of time [ $<12$ months; as identified by

530 Behrensmeyer (1978) and Fiorillo (1988)] Together, these observations suggest that the juvenile

531 lambeosaurines perished in a mass mortality event, rather than through gradual attrition (Bell \&

532 Campione, 2014; Chiba et al., 2015; Funston et al., 2016; Ullmann et al., 2017).

533 The killing mechanism for the SCBB lambeosaurines remains unknown. The

534 pathological lesion observed on a partial ilium (UALVP 60540; Fig. 9) resembles features

535 resulting from Langerhans Cell Histiocytosis inferred in other hadrosaurids, based on its smooth 
536 margin and "wrinkled" internal surface (Rothschild et al., 2020). However, it is intuitively

537 implausible that an osteologically borne disease instigated the mass mortality event. Coastal-

538 plain flooding has been interpreted as the typical source of macrofossil bonebeds throughout the

539 Upper Cretaceous of Alberta (Eberth, 2015). Like those hosting the SCBB, floodplain deposits

540 are common within Unit 3 of the Wapiti Formation, attesting to periodic inundation while the

541 formation was being deposited (Fanti \& Catuneanu, 2009). However, the absence of aquatic

542 vertebrates and the lack of either advanced hydraulic reworking or channel sediments indicate

543 that the SCBB lambeosaurines did not drown within a channel (Bell \& Campione, 2014).

544 Additionally, the laminar bone deposited near the periosteal surface of sectioned humeri may

545 indicate slower bone growth, suggesting that the SCBB lambeosaurines died during a cold or dry

546 season (Wosik et al., 2020).

Following the mass mortality event, the lambeosaurine cadavers were exposed long enough for scavenging, trampling, and disarticulation to occur but were buried before substantial weathering could take effect. The ubiquitous disarticulation in the SCBB is most likely a product

550 of skeletal immaturity, which sees juveniles disarticulating more rapidly than adults (Hill \&

551 Behrensmeyer, 1984; Horner \& Currie, 1994). Scavenging and trampling, inferred from the

552 presence of tooth marks, parallel striae, and spiral fractures, may have also contributed to

553 disarticulation. However, scavenging processes were likely minor given the low occurrence of

554 bite-marks (3.8\%; Table 5) compared to other sites, such as the Danek Bonebed (30\%; Bell \&

555 Campione, 2014), Bleriot Ferry Bonebed ( 10\%; Evans et al., 2015), and Scabby Butte

556 Bonebed: Site 2 (6.2\%; Campbell et al., 2019).

557 A significantly higher incidence of bones within Voorhies groups II and III at the SCBB $558\left(\chi^{2}=41.746, P\right.$-value $<<0.001$; Table 2$)$ indicates the selective removal of some smaller, more 
559 transportable elements. Presumably, fluvial factors were the primary sorting mechanism

560 (Voorhies, 1969), although some small elements, including haemal arches and metacarpals, were

561 preserved. Tooth marks and parallel striae suggest that scavenging and trampling, respectively,

562 occurred at the SCBB but, given their low incidence, likely represented minor sorting roles

563 compared to fluvial influences. The preservation of hadrosaurid teeth articulated within a dentary

564 (UALVP 59900) is significant because the fragile lingual sheet of bone that keeps the teeth

565 within the dentary is highly susceptible to post-mortem damage, indicating that the SCBB

566 lambeosaurines were buried before such early deterioration could occur (Bell \& Campione,

567 2014). Moreover, the scarcity of teeth within hadrosaurid bonebeds has been used to support a

568 'bloat-and-float' scenario (Gangloff \& Fiorillo, 2010), during which teeth are lost as a result of

569 hydraulic transport, following the loss of the thin lingual sheet. The presence of articulated and

570 isolated teeth in the SCBB is inconsistent with this scenario and suggests little to no transport

571 from the site of death. Although Rao's spacing test suggested a significant NE-SW preferred

572 orientation, the substantial circular variance around this modal orientation (Fig. 2) suggests a

573 generally low fluvial influence on long bone alignment. Additionally, high patchiness indices

574 and some skeletal associations suggest little reworking/transport of elements. Overall lack of

575 abrasion in the sample (Table 5) also suggests limited transport (Hunt, 1978; Fiorillo, 1988),

576 although the relationship between abrasion and transport can be highly variable (Behrensmeyer,

577 1982; Argast et al., 1987; Eaton et al., 1989). Given the above taphonomic evidence, we cannot

578 unambiguously reject that some transport of elements occurred, and thus the SCBB can be

579 conservatively regarded as a parautochthonous mass mortality bonebed.

581 Growth dynamics of the SCBB lambeosaurines 

sustained, but not rapid, growth at their time of death (Horner \& Currie, 1994; Horner et al., 584 2000; Hubner, 2012). The regions of reticular to plexiform bone preserved in the deeper parts of 585 the outer cortex indicate recent periods of rapid growth, whereas the presence of secondary 586 osteons coupled with the increased organization of the laminar bone towards the periosteal surface suggest that individuals were experiencing a slower growth rate (Horner et al., 1999; Horner et al., 2000; Huttenlocker et al., 2013). Scaling of limb bones from the SCBB to those of an articulated juvenile Lambeosaurus indicates that the individuals had attained a total body length of $\leq 4.2 \mathrm{~m}$ (Table 4; Lambeosaurus data from Farke et al., 2013), which is around half the 7-10 m total body length observed in most adult hadrosaurids or a third of the total $\sim 12 \mathrm{~m}$ length reached by giant hadrosaurids (Prieto-Márquez et al., 2012; Hone et al., 2014).

Attempts to infer hadrosaurid growth strategies from histological analyses are inescapably convoluted, to say the least. In Maiasaura peeblesorum, Horner et al. (2000) identified six distinct ontogenetic stages based on bone microstructure patterns and the total lengths of associated femora: early and late nestling, early and late juvenile, sub-adult, and adult. The SCBB lambeosaurines bear the greatest histological resemblance to the late juvenile stage, as sectioned humeri display: 1) laminar, plexiform, and reticular bone, 2) Haversian reconstruction, including secondary osteons, 3) spongiose, but not hollow, marrow cavities, and 4) no evidence of LAGs or an external fundamental system (Horner et al., 2000). Late juveniles

601 are hypothesized to exhibit moderate to high growth rates and, based on bone diametral increases, should have reached the late juvenile stage 1.1-2.4 years after hatching (Horner et al., 2000, Wosik et al., 2020). However, the SCBB lambeosaurines possibly had a different 

designation. In M. peeblesorum, 0-1 LAGs were indicative of a late juvenile growth stage

607 (Horner et al., 2000). Vanderven et al. (2014) demonstrated that, in E. regalis, LAGs occur more 608 frequently in humeri than in femora of E. regalis, a pattern thought to reflect slower humeral 609 growth. A single LAG was observed in the smallest E. regalis humerus, although this specimen was $\sim 140 \mathrm{~mm}$ longer than the humeri collected from the SCBB. LAGs were previously interpreted as representing annual interruptions in growth (Horner et al., 1999; Horner et al., 2000; Chinsamy et al., 2012; Vanderven et al., 2014; Woodward et al., 2015), and it is, therefore, possible that the lack of LAGs in the SCBB lambeosaurines means that they were not yet a year old at the time of death, however; given their considerable size, this is unlikely. Alternatively, the lack of LAGs among the sampled SCBB humeri may be environmental rather than ontogenetic (Chinsamy et al., 2012; Vanderven et al., 2014). The Wapiti Formation represents a geographic transition between Alaska's polar faunas and the more temperate zones of southern Alberta and northern Montana (Bell et al., 2014b). As such, the development of bone textural switches in Edmontosaurus sp. from Alaska could be the result of polar overwintering, with harsher seasons leading to growth interruption (Chinsamy et al., 2012), although distinct LAGs

621 have also been noted in some hadrosaurids from temperate latitudes (Horner et al., 1999).

622 Nevertheless, the lack of LAGs at the SCBB may suggest that Unit 3 of the Wapiti Formation 623 was deposited under relatively equable climatic conditions (Fanti \& Miyashita, 2009). In any 624 case, the use of LAGs to determine absolute age is evidently ambiguous, especially for humeri 625 (Horner et al., 2000; Erickson et al., 2001; Vanderven et al., 2014; Woodward et al., 2015). We, 626 therefore, adopt the more conservative approach of assigning the SCBB lambeosaurines to the 
627 late juvenile stage based on their degree of histological similarity with late juvenile individuals

628 of M. peeblesorum (Horner et al., 2000), and their overall body size.

629

630 Age segregation in hadrosaurids

631 Taphonomic data and the lack of adult or perinatal material indicate that the SCBB

632 lambeosaurine material is best interpreted as the remains of a group of late juvenile individuals

633 that perished in a single mass mortality event. Accordingly, the composition of the SCBB may

634 reflect a demographic phenomenon known as age segregation — the aggregation and segregation

635 of individuals of the same species based on age, typically in response to resource or spatial

636 limitations (Rogers \& Kidwell, 2007; Pelletier et al., 2016). Among dinosaurs, age segregation

637 has been proposed as an explanation for juvenile-dominated bonebed samples of sauropods

638 (Myers \& Fiorillo, 2009), theropods (Raath, 1990; Currie, 1998; Zanno \& Erickson, 2006;

639 Varricchio et al., 2008), ceratopsians (Gilmore, 1917; Lehman, 2006; Mathews et al., 2007; Zhao

640 et al., 2014), thyreophorans (Galton, 1982; Jerzykiewicz et al., 1993; McWhinney et al., 2004),

641 and ornithopods, including lambeosaurines (Dodson, 1971; Norman, 1987; Forster, 1990;

642 Varricchio \& Horner, 1993; Scherzer \& Varricchio, 2010; Eberth, 2015; Vila et al., 2016; Wosik

643 et al., 2020). Food is a limited resource in most ecosystems, and sympatric species often employ

644 interspecific niche partitioning strategies to minimize the adverse effects of competition (Farlow,

645 1976; du Toit \& Cumming, 1999; Lehman, 2001; Mallon \& Anderson, 2014). However,

646 ecomorphological data have only distinguished major dinosaurian clades (e.g., ceratopsians vs.

647 hadrosaurids vs. ankylosaurs), and it remains unclear how, and indeed whether, closely related

648 species may have mitigated the effects of mutual competition (Mallon \& Anderson, 2014). It is,

649 therefore, possible that in dinosaurs, such as hadrosaurids, such mitigation was achieved via 
650 intra- rather than interspecific dynamics, with juveniles and adults partitioning food based on

651 either dietary requirements and/or physiological capabilities. For instance, the fitness costs of

652 dietary synchronization in sauropods (such as those associated with movement to new foraging

653 areas and the need for more resting time) as a result of size difference between juveniles and

654 adults were possibly eased by age segregation and age-based niche partitioning, a scenario

655 supported by the existence of ontogenetically variable dental microwear patterns (Fiorillo, 1998;

656 Myers \& Fiorillo, 2009; Zhao et al., 2014; Pelletier et al., 2016). To date, the possibility of

657 similar ontogenetic variation in dental microwear has not been investigated in hadrosaurids.

658 However, younger hadrosaurids were clearly unable to reach the same maximum feeding heights

659 as adults, implying that juveniles must have had a more restricted feeding envelope unless they

660 were actively fed by mature individuals. Accordingly, the SCBB and other age-segregated

661 bonebeds (Varricchio et al., 2008; Myers \& Fiorillo, 2009; Scherzer \& Varricchio, 2010; Eberth

$662 \&$ Braman, 2012) may be a product of population-level resource partitioning strategies that

663 mitigated competition between diverse communities of megaherbivorous dinosaurs (Mallon et

664 al., 2012; Mallon \& Anderson, 2013; Mallon et al., 2013; Mallon \& Anderson, 2014).

665 An alternate explanation for age segregation at the SCBB, though one not mutually

666 exclusive with resource partitioning, is that hadrosaurid life history and breeding strategies led to

667 seasonal variation in the age structure among a population (Varricchio, 2011; Zhao et al., 2014).

668 Aggregations of hadrosaurid nesting sites indicate colonial nesting behaviours in both lowland

669 and upland areas (Horner, 1982; Tanke \& Brett-Surman, 2001; Fanti \& Miyashita, 2009). During

670 nesting times, non-breeding individuals may have segregated away from the breeding

671 population, being relatively large ( $\sim 50 \%$ of typical adult size; Table 4$)$, but potentially still

672 sexually immature (Varricchio et al., 2008; Varricchio, 2011, Wosik et al., 2020). However, such 
673 segregated groups are liable to contain a spectrum of ages (e.g., early-late juveniles; Varricchio

674 et al., 2008; Zhao et al., 2014), which is not the case for the SCBB lambeosaurines. Finally, age

675 segregation could be the result of annually cyclical parental caring behaviours, in which young

676 were reared for an extended period within a yearly cycle, as observed in most modern

677 crocodilian and avian species (Thorbjarnarson \& Hernandez, 1993; Davies, 2002). Such parental

678 caring behaviours have been inferred from multiple dinosaur bonebeds, including those of

679 hadrosaurids (Horner \& Makela, 1979), and supported by egg-adult associations (Varricchio, 680 2011).

Dinosaurs exhibited complex life histories and behavioural flexibility (e.g. Myers \&

682 Fiorillo, 2009; Varricchio, 2011), and there is still much about their palaeoecology that we do not 683 understand (Mallon \& Anderson, 2013; Mallon et al., 2013; Mallon \& Anderson, 2014).

684 Moreover, as we cannot readily distinguish between males and females in the dinosaur fossil 685 record, we cannot reject the possibility that age-segregated dinosaur bonebeds were sexually 686 segregated as well (Myers \& Fiorillo, 2009; Pelletier et al., 2016), as was implied by Tanke 687 (2004) in his original report, referring to the assemblage as a 'bachelor herd'. Regardless of 688 whether sex-segregation was typical of juvenile hadrosaurid bonebeds, such deposits offer a 689 wealth of insights into growth and social behaviour in these ubiquitous herbivores and will 690 undoubtedly reward further research.

691

\section{Conclusion}

This study marks the first formal description of the Spring Creek Bonebed and the first definitive documentation of lambeosaurines from the Wapiti Formation, here preserved within 
695 Unit 3. A total of 351 specimens were thus far collected from the bonebed, from which we

696 identified a minimum of eight juvenile individuals based on non-overlapping humeri.

697 Interestingly, unique spatiotemporal and conflicting morphological signatures hint at the

698 presence of a new lambeosaurine species within the formation. However, given their ontogenetic

699 state and the difficulties associated with identifying even complete juvenile specimens to a genus

700 or species (Evans et al., 2005; Brink et al., 2014), we feel that a conservative indeterminate

701 Lambeosaurinae designation is the most appropriate at this time.

702 The seemingly exclusive preservation of a single age class adds to our understanding of

703 dinosaurian life histories, further supporting that breeding, seasonality, and/or dietary

704 partitioning may contribute to dinosaur demographics. Future research into macrofossil

705 bonebeds, particularly from the Wapiti Formation, will undoubtedly provide a greater

706 understanding of dinosaur diversity, distribution, and life history strategies during the final stages

707 of the Mesozoic.

\section{Acknowledgements}

710 This study was completed as part of BH's Master of Science degree at the University of New

711 England, Australia, supervised by NEC and PRB. Thanks are given to John Scannella and Amy

712 Atwater (Museum of the Rockies), Kevin Seymour (Royal Ontario Museum), Brandon Strilisky

713 and Rebecca Sanchez (Royal Tyrell Museum of Paleontology), and Cam Reed and Calla Scott

714 (Philip J. Currie Dinosaur Museum) for access to and help with their respective collections.

715 Special thanks to Malcolm Lambert for preparing histological samples of TMP specimens and to

716 Russell Bicknell (University of New England) for capturing of images for supplementary figure 
717 2C and D. We are grateful to Grande Prairie Regional College, who facilitated fieldwork in the

718 Peace Region of northwestern Alberta, and to the many volunteers during the 2018 and 2019

719 BADP expeditions. This research was funded by a Research Training Program and Rural and

720 Regional Enterprise scholarships to BH, a Dinosaur Research Institute (DRI) Student Project

721 Grant to BH, a DRI Dinosaur Fieldwork in Western Canada to NEC and MJV, an Australian

722 Research Council Discovery Early Career Research Award to NEC (DE190101423), and a

723 Natural Sciences and Engineering Research Council Discovery Grant (RGPIN-2017-06246) and

724 an endowment associated with the Philip J. Currie Professorship at the University of Alberta to

725 CS. The authors would also like to thank the editor and reviewers for their comments and help

726 getting this study over the line.

727

\section{References}

729

730

731

732

733

734

735

736

737
Argast, S., Farlow, J. O., Gabet, R. M., \& Brinkman, D. L. (1987). Transport-induced abrasion of fossil reptilian teeth: implications for the existence of Tertiary dinosaurs in the Hell Creek Formation, Montana. Geology, 15(10), 927-930.

Badgley, C. (1986). Taphonomy of Mammalian Fossil Remains from Siwalik Rocks of Pakistan. Palaeobiology, 12(2), 119-142.

Behrensmeyer, A. K. (1978). Taphonomic and ecologic information from bone weathering. Paleobiology, $4(2), 150-162$.

Behrensmeyer, A. K. (1982 ). Time Resolution in Fluvial Vertebrate Assemblages. Paleobiology, 8(3), 211227. 
738

739

740

741

742

743

744

745

746

747

748

Behrensmeyer, A. K. (1991). Terrestrial Vertebrate Accumulations. In P. A. Allison \& D. E. G. Briggs (Eds.), Taphonomy: Releasing the Data Locked in the Fossil Record (Vol. 9, pp. 291-335). New York: Plenum Press.

Behrensmeyer, A. K., Gordon, A. K., \& Yanagi, K. D. (1986). Trampling as a cause of bone surface damage and pseudo-cutmarks. Nature, 319(6056), 768-771.

Bell, P. R. (2011a). Cranial Osteology and Ontogeny of Saurolophus angustirostris from the Late Cretaceous of Mongolia with Comments on Saurolophus osborni from Canada. Acta Palaeontologica Polonica, 56(4), 703-722. doi:10.4202/app.2010.0061

Bell, P. R. (2011b). Redescription of the skull of Saurolophus osborni Brown 1912 (Ornithischia: Hadrosauridae). Cretaceous Research, 32(1), 30-44. doi:10.1016/j.cretres.2010.10.002

Bell P. R., Brink K. S. (2013). Kazaklambia convincens comb. nov., a primitive juvenile lambeosaurine from the Santonian of Kazakhstan. Cretaceous Research. 45:265-274.

Bell, P. R., \& Campione, N. E. (2014). Taphonomy of the Danek Bonebed: a monodominant Edmontosaurus (Hadrosauridae) bonebed from the Horseshoe Canyon Formation, Alberta. Canadian Journal of Earth Sciences, 51(11). doi:10.1139/cjes-2014-0062

Bell, P. R., \& Currie, P. J. (2016). A high-latitude dromaeosaurid, Boreonykus certekorum, gen. et sp. nov. (Theropoda), from the upper Campanian Wapiti Formation, west-central Alberta. Journal of Vertebrate Paleontology, 36(1). doi:10.1080/02724634.2015.1034359

Bell, P. R., Fanti, F., Currie, P. J., \& Arbour, V. M. (2014a). A Mummified Duck-Billed Dinosaur with a SoftTissue Cock's Comb. Current Biology, 24(1), 70-75. doi:10.1016/j.cub.2013.11.008

Bell, P. R., Fanti, F., \& Sissons, R. (2013). A possible pterosaur manus track from the Late Cretaceous of Alberta. Lethaia, 46, 274-279. 
760

761

762

763

764

765

766

767

768

769

770

771

772

773

774

775

776

777

778

779

780

781

782

783

Bell, P. R., Sissons, R., Burns, M. E., Fanti, F., \& Currie, P. J. (2014b). New Saurolophine Material from the Upper Campanian-lower Maastrichtian Wapiti Formation, West-Central Alberta. In D. Eberth \& D. C. Evans (Eds.), Hadrosaurs (pp. 174-190). Bloomington, IN: Indiana University Press.

Blob, R. W., \& Badgley, C. (2007). Numerical Methods for Bonebed Analysis. In R. R. Rogers, D. A. Eberth, \& A. R. Fiorillo (Eds.), Bonebeds: Genesis, Analysis, and Paleobiological Significance (pp. 333396). Chicago and London: The University of Chicago Press.

Brink, K. S., Zelenitsky, D. K., Evans, D. C., Therrien, F., \& Horner, J. R. (2011). A sub-adult skull of Hypacrosaurus stebingeri (Ornithischia: Lambeosaurinae): anatomy and comparison. Historical Biology, 23(1), 63-72. doi:10.1080/08912963.2010.499169

Brink, K. S., D. K. Zelenitsky, D. C. Evans, J. R. Horner, and F. Therrien. 2014. Cranial Morphology and Variation in Hypacrosaurus stebingeri (Ornithischia: Hadrosauridae). In D. Eberth \& D. C. Evans (Eds.), Hadrosaurs (pp. 245-265). Bloomington, IN: Indiana University Press.

Britt, B. B., Eberth, D. A., Scheetz, R. D., Greenhalgh, B. W., \& Stadtman, K. L. (2009). Taphonomy of debris-flow hosted dinosaur bonebeds at Dalton Wells, Utah (Lower Cretaceous, Cedar Mountain Formation, USA). Palaeogeography, Palaeoclimatology, Palaeoecology, 280(1-2), 122. doi:10.1016/j.palaeo.2009.06.004

Campbell, J. A., Ryan, M. J., \& Anderson, J. F. (2019). A taphonomic analysis of a multitaxic bonebed from the St. Mary River Formation (uppermost Campanian to lowermost Maastrichtian) of Alberta, dominated by cf. Edmontosaurus regalis (Ornithischia: Hadrosauridae), with significant remains of Pachyrhinosaurus canadensis (Ornithischia: Ceratopsidae). Canadian Journal of Earth Sciences, 00, 1-13.

Campione, N. E., \& Evans, D. C. (2011). Cranial Growth and Variation in Edmontosaurs (Dinosauria: Hadrosauridae): Implications for Latest Cretaceous Megaherbivore Diversity in North America. PLoS One, 6(9), e25186. doi:10.1371/journal.pone.0025186 
784 Chiba, K., Ryan, M. J., Braman, D. R., Eberth, D. A., Scott, E. E., Brown, C. M., ... Evans, D. C. (2015).

785 Taphonomy of a Monodominant Centrosaurus Apertus (Dinosauria: Ceratopsia) Bonebed from

786 the Upper Oldman Formation of Southeastern Alberta. Palaios, 30(9), 655-667.

787 doi:10.2110/palo.2014.084

788

789

790

791

792

793

794

795

796

797

798

799

800

801

802

803

804

805

806
Chinsamy, A., Thomas, D. B., Tumarkin-Deratzian, A. R., \& Fiorillo, A. R. (2012). Hadrosaurs Were Perennial Polar Residents. The Anatomical Record, 295(4), 610-614. doi:10.1002/ar.22428

Christians, J. P. (1992). Taphonomy and Sedimentology of the Mason Dinosaur Quarry. Hell Creek Formation (Upper Cretaceous), South Dakota. (MSc). University of Wisconsin,

Currie, P. J. (1998). Possible evidence of gregarious behavior in tyrannosaurids. GAIA, 15, $217-277$.

Currie, P. J., Langston Jr, W., \& Tanke, D. H. (2008a). A new species of Pachyrhinosaurus (Dinosauria, Ceratopsidae) from the Upper Cretaceous of Alberta, Canada. A New Horned Dinosaur from an Upper Cretaceous Bone Bed in Alberta. In P. J. Currie, W. Langston Jr, \& D. H. Tanke (Eds.), A New Horned Dinosaur from an Upper Cretaceous Bone Bed in Alberta. Ottawa: National Research Council of Canada (pp. 1-108). Ottawa: NRC Research Press.

Currie, P. J., Langston, J. W., \& Tanke, D. H. (2008b). A new species of Pachyrhinosaurus (Dinosauria, Ceratopsidae) from the Upper Cretaceous of Alberta, Canada.

Davies, S. J. J. F. (2002). Ratites and Tinamous. Oxford: Ofxord University Press.

Dodson, P. (1971). Sedimentology and taphonomy of the Oldman formation (Campanian), dinosaur provincial park, Alberta (Canada). Palaeogeography, Palaeoclimatology, Palaeoecology, 10(1), 21-74.

du Toit, J. T., \& Cumming, D. H. M. (1999). Functional significance of ungulate diversity in African savannas and the ecological implications of the spread of pastoralism. Biodiversity \& Conservation, 8, 1643-1661.

Peer) reviewing PDF | (2020:11:55729:1:1:NEW 22 Mar 2021) 
807 Eaton, J. G., Kirkland, J. I., \& Doi, K. (1989). Evidence of Reworked Cretaceous Fossils and their Bearing 808 on the Existence of Tertiary Dinosaurs. Palaios, 4, 281-286.

809 Eberth, D. A. (2015). Origins of dinosaur bonebeds in the Cretaceous of Alberta, Canada. Canadian Journal of Earth Sciences, 52, 655-681. doi:10.1139/cjes-2014-0200

811

812

813

814

Eberth, D. A., \& Braman, D. R. (2012). A revised stratigraphy and depositional history for the Horseshoe Canyon Formation (Upper Cretaceous), southern Alberta plains. Canadian Journal of Earth Sciences, 49(9), 1053-1086.

Eberth, D. A., \& Currie, P. J. (2010). Stratigraphy, sedimentology, and taphonomy of the Albertosaurus bonebed (upper Horseshoe Canyon Formation; Maastrichtian), southern Alberta, Canada. Canadian Journal of Earth Sciences, 47(9), 1119-1144. doi:10.1139/E10-045

Eberth, D. A., Evans, D. C., Brinkman, D. B., Therrien, F., Tanke, D. H., \& Russell, L. S. (2013). Dinosaur biostratigraphy of the Edmonton Group (Upper Cretaceous), Alberta, Canada: evidence for climate influence. Canadian Journal of Earth Sciences, 50, 701-726.

Eberth, D. A., \& Getty, M. A. (2005). Ceratopsian bonebeds: occurence, origins, and significance. In P. J. Currie \& E. B. Koppelhus (Eds.), Dinosaur Provincial Park: A Spectacular Ancient Ecosystem Revealed (pp. 501-536). Bloomington, Indianapolis: Indiana University press.

Eberth, D. A., \& Kamo, S. L. (2020). High-precision U-Pb CA-ID-TIMS dating and chronostratigraphy of the dinosaur-rich Horseshoe Canyon Formation (Upper Cretaceous, Campanian-Maastrichtian), Red Deer River valley, Alberta, Canada. Canadian Journal of Earth Sciences, 00, 1-18.

Eberth, D. A., Rogers, R. R., \& Fiorillo, A. R. (2007a). A practical approach to the study of bonebeds. In R. R. Rogers, D. A. Eberth, \& A. R. Fiorillo (Eds.), Bonebeds: genesis, analysis, and paleobiological significance (pp. 256-331). Chicago and London: University of Chicago.

Eberth, D. A., Shannon, M., \& Noland, B. G. (2007b). A Bonebeds Database: Classification, Biases, and Patterns of Occurence. In R. R. Rogers, D. A. Eberth, \& A. R. Fiorillo (Eds.), Bonebeds: Genesis, 
Analysis, and Palaeobiological Significance (pp. 103-220). Chicago and London: The University of Chicago Press.

Egi, N., \& Weishampel, D. B. (2002). Morphometric analyses of humeral shapes in hadrosaurids (Ornithopoda, Dinosauria). Senckenbergiana lethaea, 82(1), 43-57.

Erickson, G. M., Rogers, K. C., \& Yerby, S. A. (2001). Dinosaurian growth patterns and rapid avian growth rates. Nature, $412,429-433$.

Evans, D. C. (2010). Cranial anatomy and systematics of Hypacrosaurus altispinus, and a comparative analysis of skull growth in lambeosaurine hadrosaurids (Dinosauria: Ornithischia). Zoological Journal of the Linnean Society, 159(2), 398-434. doi:10.1111/j.1096-3642.2009.00611.x

Evans, D. C., Eberth, D. A., Ryan, M. I. J., \& Therrien, F. (2015). Hadrosaurid (Edmontosaurus) bonebeds from the Horseshoe Canyon Formation (Horsethief Member) at Drumheller, Alberta, Canada: geology, preliminary taphonomy, and significance. Canadian Journal of Earth Sciences, 52(8), 642-654. doi:10.1139/cjes-2014-0184

Evans, D. C., Forster, C. A., \& Reisz, R. R. (2005). The Type Specimen of Tetragonosaurus erectofrons (Ornithischia: Hadrosauridae) and the Identification of Juvenile Lambeosaurines. In P. J. Currie \& E. B. Koppelhus (Eds.), Dinosaur Provincial Park: a spectacular ancient ecosystem revealed (pp. 349-366): Indiana University Press.

Evans, D. C., \& Reisz, R. R. (2007). Anatomy and Relationships of Lambeosaurus magnicristatus, a crested hadrosaurid dinosaur (Ornithischia) from the Dinosaur Park Formation, Alberta. Journal of Vertebrate Paleontology, 27(2), 373-393. doi:10.1671/0272-4634(2007)27[373:Aarolm]2.0.Co;2

Evans, D. C., Reisz, R. R., \& Dupuis, K. (2007). A juvenile Parasaurolophus (Ornithischia: Hadrosauridae) braincase from Dinosaur Provincial Park, Alberta, with comments on crest ontogeny in the genus. Journal of Vertebrate Paleontology, 27(3), 642-650. doi:10.1671/0272- 
855 Evans, D. C., Sues, H., Bavington, R., \& Campione, N. E. (2009). An unusual hadrosaurid braincase from

856

857

858

859

860

861

862

863

864

865

866

867

868

869

870

871

872

873

874

875

876

877 the Dinosaur Park Formation and the biostratigraphy of Parasaurolophus (Ornithischia:

Lambeosaurinae) from southern Alberta. Canadian Journal of Earth Sciences, 46(11), $791-800$. doi:10.1139/e09-050

Fanti, F., Bell, P. R., \& Sissons, R. L. (2013). A diverse, high-latitude ichnofauna from the Late Cretaceous Wapiti Formation, Alberta, Canada. Cretaceous Research, 41, 256-269.

Fanti, F., \& Catuneanu, O. (2009). Stratigraphy of the Upper Cretaceous Wapiti Formation, west-central Alberta, Canada. Canadian Journal of Earth Sciences, 46(4), 263-286. doi:10.1139/e09-020

Fanti, F., \& Catuneanu, O. (2010). Fluvial sequence stratigraphy: the Wapiti Formation, West-Central Alberta, Canada. Journal of Sedimentary Research, 80(4), 320-338. doi:10.2110/jsr.2010.033

Fanti, F., Currie, P. J., \& Burns, M. E. (2015). Taphonomy, age, and paleoecological implication of a new Pachyrhinosaurus (Dinosauria: Ceratopsidae) bonebed from the Upper Cretaceous (Campanian) Wapiti Formation of Alberta, Canada. Canadian Journal of Earth Sciences, 52(4), 250-260. doi:10.1139/cjes-2014-0197

Fanti, F., \& Miyashita, T. (2009). A high latitude vertebrate fossil assemblage from the Late Cretaceous of west-central Alberta, Canada: evidence for dinosaur nesting and vertebrate latitudinal gradient. Palaeogeography, Palaeoclimatology, Palaeoecology, 275(1-4), 37-53. doi:10.1016/j.palaeo.2009.02.007

Farke, A. A., Chok, D. J., Herrero, A., Scolieri, B., \& Werning, S. (2013). Ontogeny in the tube-crested dinosaur Parasaurolophus (Hadrosauridae) and heterochrony in hadrosaurids. PeerJ, 1, e182. doi:10.7717/peerj.182

Farlow, J. O. (1976). A consideration of the trophic dynamics of a Late Cretaceous large dinosaur community (Oldman Formation). Ecology, 57, 841-857.

Peer) reviewing PDF | (2020:11:55729:1:1:NEW 22 Mar 2021) 
878 Fiorillo, A. R. (1988). Taphonomy of Hazard Homestead Quarry (Ogallala Group), Hitchcook County, 879 Nebraska. Contributions to Geology, 26(2), 57-97.

880 Fiorillo, A. R. (1998). Dental microwear patterns of the sauropod dinosaurs Camarasaurus and

881

882

883

884

885

886

887

888

889

890

891

892

893

894

895

896

897

898

899

900

901
Diplodocus: evidence for resource partitioning in the Late Jurassic of North America. Historical Biology, 13, 1-16.

Forster, C. A. (1990). Evidence for juvenile groups in the ornithopod dinosaur Tenontosaurus tilletti Ostrom. Journal of Paleontology, 64(1), 164-165.

Fowler, D. W. (2017). Revised geochronology, correlation, and dinosaur stratigraphic ranges of the Santonian-Maastrichtian (Late Cretaceous) formations of the Western Interior of North America. PLoS One, 12(11).

Funston, G. F., Currie, P. J., Eberth, D. A., Ryan, M. J., Chinzorig, T., Badamgarav, D., \& Longrich, N. R. (2016). The first oviraptorosaur (Dinosauria: Theropoda) bonebed: evidence of gregarious behaviour in a maniraptoran theropod. Scientific Reports, 6(35782).

Galton, P. M. (1982). Juveniles of the stegosaurian dinosaur Stegosaurus from the Upper Jurassic of North America. Journal of Vertebrate Paleontology, 2, 47-62.

Gangloff, R. A., \& Fiorillo, A. R. (2010). Taphonomy and Paleoecology of a Bonebed from the Prince Creek Formation, North Slope, Alaska. Palaios, 25(5-6), 299-317. doi:10.2110/palo.2009.p09$103 r$

Gates, T. A., Sampson, S. D., De Jesús, C. R. D., Zanno, L. E., Eberth, D., Hernandez-Rivera, R., . . . Kirkland, J. I. (2007). Velafrons coahuilensis, a new lambeosaurine hadrosaurid (Dinosauria: Ornithopoda) from the late Campanian Cerro del Pueblo Formation, Coahuila, Mexico. Journal of Vertebrate Paleontology, 27(4), 917-930. doi:10.1671/0272-4634(2007)27[917:Vcanlh]2.0.Co;2

Getty, M., Eberth, D. A., Brinkman, D. B., \& Ryan, M. (1998). Taphonomy of three Centrosaurus bonebeds in the Dinosaur Park Formation, Alberta. Journal of Vertebrate Paleontology, 18.

PeerJ reviewing PDF | (2020:11:55729:1:1:NEW 22 Mar 2021) 
902 Gilmore, C. W. (1917). Brachyceratops, a ceratopsian dinosaur from the Two Medicine Formation of 903 Montana with notes on associated reptiles. United States Geological Survey Professional Paper, $904 \quad 103,1-45$.

905 Godefroit, P., Bolotsky, Y. L., \& Van Itterbeeck, J. (2004). The lambeosaurine dinosaur Amurosaurus 906 riabinini, from the Maastrichtian of Far Eastern Russia. Acta Palaeontologica Polonica, 49(4).

907 Henderson, D. M. 2014. Duck soup: the floating fates of hadrosaurs and ceratopsians at Dinosaur 908 Provincial Park. Pp. 459-466 in D. A. Eberth and D. C. Evans, eds. Hadrosaurs. Indiana University $909 \quad$ Press, Bloomington

910 Hill, A., \& Behrensmeyer, A. K. (1984). Disarticulation patterns in some modern East African mammals. $911 \quad$ Palaeobiology, 10(3), 366-376.

912 Hone, D. W., Sullivan, C., Zhao, Q., Wang, K., \& Xu, X. (2014). Body size distribution in a death assemblage of a colossal hadrosaurid from the Upper Cretaceous of Zhucheng, Shandong Province, China. In D. A. Eberth \& D. C. Evans (Eds.), Hadrosaurs (pp. 524-531). Bloomington: Indiana University Press.

916 Horner, J. R. (1982). Evidence of colonial nesting and 'site fidelity' among ornithschian dinosaurs. Nature, 297, 675-676.

Horner, J. R. (1983). Cranial Osteology and Morphology of the Type Specimen of Maiasaura peeblesorum (Ornithischia: Hadrosauridae), with Discussion of Its Phylogenetic Position. Journal of Vertebrate Paleontology, 3(1), 29-38.

Horner, J. R. (1992). Cranial morphology of Prosaurolophus (Ornithischia: Hadrosauridae) with descriptions of two new hadrosaurid species and an evaluation of hadrosaurid phylogenetic relationships. Museum of the Rockies Occasional Paper, 2, 1-119. Paleontology, 19(4), 607-611. doi:10.1080/02724634.1999.10011174 
926 Horner, J. R., \& Currie, P. J. (1994). Embryonic and neonatal morphology and ontogeny of a new species

927

928

929

930

931

932

933

934

935

936

937

938

939

940

941

942

943

944

945

946

947

948

949 of Hypacrosaurus (Ornithischia, Lambeosauridae) from Montana and Alberta. In K. Carpenter, K. F. Hirsch, \& J. R. Horner (Eds.), Dinosaur Eggs and Babies (pp. 312-336). Cambridge: University of Cambridge.

Horner, J. R., De Ricqles, A., \& Padian, K. (2000). Long bone histology of the hadrosaurid dinosaur Maiasaura peeblesorum growth dynamics and physiology based on an ontogenetic series of skeletal elements. Journal of Vertebrate Paleontology, 20(1), 115-129.

Horner, J. R., \& Makela, R. (1979). Nest of juveniles provides evidence of family structure among dinosaurs. Nature, 282(5736).

Horner, J. R., Ricqles, A. D., \& Padian, K. (1999). Variation in skeletolochronology indicators: Implications for age assessment and physiology. Palaeobiology, 25(3), 295-304.

Horner, J. R., Weishampel, D. B., \& Forster, C. A. (2004). Hadrosauridae. In D. B. Weishampel, P. Dodson, \& H. Osmolska (Eds.), The Dinosauria, second edition (pp. 438-463). Berkeley: University of California Press.

Hubner, T. R. (2012). Bone Histology in Dysalotosaurus lettowvorbecki (Ornithischia: Iguanodontia) Variation, Growth, and Implications. PLoS One, 7(1).

Hunt, R. M. (1978). Depositiona setting of a Miocene mammal assemblage, Sioux County, Nebraska (U.S.A.). Palaeogeography, Palaeoclimatology, Palaeoecology, 24, 1-52.

Huttenlocker, A. K., Woodward, H. N., \& Hall, B. K. (2013). The Biology of Bone. Berkeley: University of California Press.

Jerzykiewicz, T., Currie, P. J., Eberth, D. A., Johnston, P. A., Koster, E. H., \& Zheng, J. J. (1993). Djadokhta Formation correlative strata in Chinese Inner Mongolia: an overview of the stratigraphy, sedimentary geology, and paleontology and comparisons with the type locality in the pre-Altai Gobi. Canadian Journal of Earth Sciences, 30(10), 2180-2195.

Peer] reviewing PDF | (2020:11:55729:1:1:NEW 22 Mar 2021) 
950 Keenan, S. W., \& Scannella, J. B. (2014). Paleobiological implications of a Triceratops bonebed from the 951 Hell Creek Formation, Garfield County, northeastern Montana. In G. P. Wilson, W. A. Clemens, J. 952 R. Horner, \& J. H. Hartman (Eds.), Through the End of the Cretaceous in the Type Locality of the Hell Creek Formation in Montana and Adjacent Areas (Vol. 503): Geological Society of America.

954

955

956

957

958

959

960

961

962

963

964

965

966

967

968

969

970

971
Lehman, T. M. (2001). Late Cretaceous dinosaur provinciality. In D. H. Tanke \& K. Carpenter (Eds.), Mesozoic vertebrate life (pp. 310-328). Bloomington: Indiana University Press.

Lehman, T. M. (2006). Growth and Population Age Structure in the Horned Dinosaur Chasmosaurus. In K. Carpenter (Ed.), Horns and Beaks: Ceratopsian and Ornithopod Dinosaurs (pp. 259-318). Bloomington and Indianapolis: Indiana University Press.

Lucas, S. G., \& Sullivan, R. M. (2006). The Kirtlandian land-vertebrate "age"-faunal composition, temporal position and biostratigraphic correlation in the nonmarine Upper Cretaceous of western North America. New Mexico Museum of Natural History and Science Bulletin, 35, 7-29.

Lucas, S. G., Sullivan, R. M., Lichtig, A. J., Dalman, S. G., \& Jasinski, S. E. (2016). Late Cretaceous dinosaur biogeography and endemism in the Western Interior Basin, North America: a critical reevaluation. New Mexico Museum of Natural History and Science Bulletin, 71, 195-213.

Lull, R. S., \& Wright, N. E. (1942). Hadrosaurian Dinosaurs of North America. Geological Society of America - Special Papers, 40.

Mallon, J. C., \& Anderson, J. S. (2013). Skull Ecomorphology of Megaherbivorous Dinosaurs from the Dinosaur Park Formation (Upper Campanian) of Alberta, Canada. PLoS One, 8(7).

Mallon, J. C., \& Anderson, J. S. (2014). Implications of beak morphology for the evolutionary paleoecology of the megaherbivorous dinosaurs from the Dinosaur Park Formation (upper Campanian) of Alberta, Canada. Palaeogeography Palaeoclimatology Palaeoecology, 394, $29-41$.

Peer] reviewing PDF | (2020:11:55729:1:1:NEW 22 Mar 2021) 
972 Mallon, J. C., Evans, D. C., Ryan, M. J., \& Anderson, J. S. (2012). Megaherbivorous dinosaur turnover in

973 the Dinosaur Park Formation (upper Campanian) of Alberta, Canada. Palaeogeography,

974 Palaeoclimatology, Palaeoecology, 350, 124-138.

975 Mallon, J. C., Evans, D. C., Ryan, M. J., \& Anderson, J. S. (2013). Feeding height stratification among the

976 herbivorous dinosaurs from the Dinosaur Park Formation (upper Campanian) of Alberta,

$977 \quad$ Canada. BMC Ecol.

978 Mathews, J., Henderson, M., \& Williams, S. (2007). Taphonomy and sedimentology of the first known

979 Triceratops bonebed, Carter County Montana. Journal of Vertebrate Paleontology, 27(3), 114a-

980 114a. Retrieved from <Go to ISI : //WOS:000249535400378

981 McGarrity, C. T., Campione, N. E., \& Evans, D. C. (2013). Cranial anatomy and variation inProsaurolophus

982

983 maximus(Dinosauria: Hadrosauridae). Zoological Journal of the Linnean Society, 167(4), 531-568.

984

McWhinney, L., Matthias, A., \& Carpenter, K. (2004). Corticated pressure erosions, or "pitting," in

985 osteodermal ankylosaur armor. Journal of Vertebrate Paleontology, 24, 92A.

986

Morris, W. J. (1970). Hadrosaurian dinosaur bills: morphology and function. Los Angeles County Museum 987 Contributions in Science, 193.

988

Myers, T. S., \& Fiorillo, A. R. (2009). Evidence for gregarious behavior and age segregation in sauropod dinosaurs. Palaeogeography, Palaeoclimatology, Palaeoecology, 274(1-2), 96-104.

990 doi:10.1016/j.palaeo.2009.01.002

991

Norman, D. B. (1987). A mass-accumulation of vertebrates from the Lower Cretaceous of Nehden (Sauerland), West-Germany. Proveedings of the Royal Society London Series B, 230, 215-255.

Ostrom, J. H. (1961). Cranial Morphology of the Hadrosaurian Dinosaurs of North America. Bulletin of the American Museum of Natural History, 122, 35-186. 
995

996

997

998

999

1000

1001

1002

1003

1004

1005

1006

1007

1008

1009

1010

1011

1012

1013

1014

1015

1016

1017

1018

Ostrom, J. H. (1963). Parasaurolophus cyrtocristatus: A Crested Hadrosaurian Dinosaur from New Mexico. Chicago Natural History Museum, 14(8).

Parks, W. A. (1922). Parasaurolophus walkeri: A New Genus and Species of Crested Trachodont Dinosaur. University of Toronto Studies, Geological Series, 13, 1-32.

Pelletier, L., Chiaradia, A., Kato, A., \& Ropert-Coudert, Y. (2016). Fine-scale spatial age segregation in the limited foraging area of an inshore seabird species, the little penguin. Oecologia, 176(2), 399408.

Peterson, J. E., Joseph, E., \& Bigalke, C. L. (2013). Hydrodynamic Behaviours of Pachycephalosaurid Domes in Controlled Fluvial Settings: A Case Study in Experimental Dinosaur Taphonomy. Palaios, 28, 285-292. doi:10.2110/palo.2013.p13-003r

Prieto-Márquez, A. (2010). Global phylogeny of hadrosauridae (Dinosauria: Ornithopoda) using parsimony and Bayesian methods. Zoological Journal of the Linnean Society, 159, 435-502.

Prieto-Márquez, A. (2012). The skull and appendicular skeleton of Gryposaurus latidens, a saurolophine hadrosaurid (Dinosauria: Ornithopoda) from the early Campanian (Cretaceous) of Montana, USA. Canadian Journal of Earth Sciences, 49, 510-532.

Prieto-Márquez, A., Chiappe, L. M., \& Joshi, S. H. (2012). The Lambeosaurine Dinosaur Magnapaulia laticaudus from the Late Cretaceous of Baja California, Northwestern Mexico. PLoS One, 7(6), e38207. doi:10.1371/journal.pone.0038207

Prieto-Márquez, A., \& Gutarra, S. (2016). The 'duck-billed' dinosaurs of Careless Creek (Upper Cretaceous of Montana, USA), with comments on hadrosaurid ontogeny. Journal of Paleontology, 90(1), 133-146. Retrieved from https://doi.org/10.1017/jpa.2016.42

Prieto-Márquez, A., \& Norrell, M. A. (2010). Anatomy and Relationships of Gilmoreosaurus mongoliensis (Dinosauria: Hadrosauroidea) from the Late Cretaceous of Central Asia. American Museum Novitates, 3694.

Peer) reviewing PDF | (2020:11:55729:1:1:NEW 22 Mar 2021) 
1019 Raath, M. A. (1990). Morphological variation in small theropods and its meaning in systematics:

1020

1021

1022

1023

1024

1025

1026

1027

1028

1029

1030

1031

1032

1033

1034

1035

1036

1037

1038

1039

1040

1041

1042 evidence from Syntarsus rhodesiensis. In K. Carpenter \& P. J. Currie (Eds.), Dinosaur Systematics: Approaches and Perspectives (pp. 92-105). Cambridge: Cambridge University Press.

Rogers, R. R., Eberth, D. A., \& Fiorillo, A. R. (2007). Bonebeds: Genesis, Analysis, and Paleobiological Significance (R. R. Rogers, D. A. Eberth, \& A. R. Fiorillo Eds.). Chicago and London: The University of Chicago Press.

Rogers, R. R., \& Kidwell, M. (2007). A Conceptual Framework for the Genesis and Analysis of Vertebrate Skeletal Concentrations. In R. Rogers, D. Eberth, \& A. Fiorillo (Eds.), Bonebeds: Genesis, analysis, and paleobiological significance (pp. 1-65). Chicago and London: The University of Chicago Press.

Rothschild, B. M., Tanke, D., Rühli, F., Pokhojaev, A., \& May, H. (2020). Suggested Case of Langerhans Cell Histiocytosis in a Cretaceous dinosaur. Scientific Reports, 10(2203), 1-10. Retrieved from https://doi.org/10.1038/s41598-020-59192-z

Ryan, M. J., \& Evans, D. C. (2005). Ornithischian Dinosaurs. In P. J. Currie \& E. B. Koppelhus (Eds.), Dinosaur Provincial Park: a spectacular ancient ecosystem revealed (pp. 312-348). Bloomington: Inidana University Press.

Sampson, S. D., Loewen, M. A., Farke, A. A., Roberts, E. M., Forster, C. A., Smith, J. A., \& Titus, A. L. (2010). New Horned Dinosaurs from Utah Provide Evidence for Intracontinental Dinosaur Endemism. PLoS One, 5(9), e12292. doi:10.1371/journal.pone.0012292

Scherzer, B. A., \& Varricchio, D. J. (2010). Taphonomy of a Juvenile Lambeosaurine Bonebed from the Two Medicine Formation (Campanian) of Montana, United States. Palaios, 25(11-12), 780-795. doi:10.2110/palo.2009.p09-143r

Slowiak, J., Szczygielski, T., Ginter, M., \& Fostowicz-Frelik, Ł. (2020). Uninterrupted Growth in a NonPolar Hadrosaur Explains the Gigantism Among Duck-Billed Dinosaurs. Palaeontology, 1-21. doi:10.1111/pala.12473 
1043 Takasaki, R., Fiorillo, A. R., Kobayashi, Y., Tykoski, R. S., \& McCarthy, P. J. (2019). The First Defnite $1044 \quad$ Lambeosaurine Bone From the Liscomb Bonebed of the Upper Cretaceous Prince Creek 1045 Formation, Alaska, United States. Scientific Reports, 9(5384). Retrieved from https://doi.org/10.1038/s41598-019-41325-8

Tanke, D., \& Brett-Surman, M. K. (2001). Evidence of hatchling and nesting-size hadrosaurs (Reptilia: Ornithischia) from Dinosaur Provincial park (Dinosaur Park Formation: Campanian), Alberta. Mesozoic vertebrate life.

Tanke, D. H. (2004). Mosquitoes and Mud: The 2003 Royal Tyrrell Museum Expedition to the Grande Prairie Region (northwestern Alberta, Canada). Alberta Palaeontological Society Bulletin, 19(2), 3-31.

Thorbjarnarson, J. B., \& Hernandez, G. (1993). Reproductive ecology of the Orinoco crocodile (Crocodylus intermedius) in Venezuela. Journal of herpetology, 363-370.

Ullmann, P. V., Shaw, A., Nellermoe, R., \& Lacovara, K. J. (2017). Taphonomy of the Standing Rock Hadrosaur Site, Corson County, South Dakota. Palaios, 32(12), 779-796.

Vanderven, E., Burns, M. E., \& Currie, P. J. (2014). Histologic growth dynamic study of Edmontosaurus doi:10.2110/palo. 2017.060

Varricchio, D. J. (1995). Taphonomy of Jacks-Birthday Site, a Diverse Dinosaur Bonebed from the Upper regalis (Dinosauria: Hadrosauridae) from a bonebed assemblage of the Upper Cretaceous Horseshoe Canyon Formation, Edmonton, Alberta, Canada. Canadian Journal of Earth Sciences, 51(11), 1023-1033. doi:10.1139/cjes-2014-0064

1065

Varricchio, D. J. (2011). A distinct dinosaur life history? Historical Biology, 23(1), 91-107. doi:10.1080/08912963.2010.500379 
1067 Varricchio, D. J., \& Horner, J. R. (1993). Hadrosaurid and lambeosaurid bone beds from the Upper

1068 Cretaceous Two Medicine Formation of Montana: taphonomic and biologic implications. 1069 Canadian Journal of Earth Sciences, 30(5), 997-1006.

1070 Varricchio, D. J., Sereno, P. C., Xijin, Z., Lin, T., Wilson, J. A., \& Lyon, G. H. (2008). Mud-Trapped Herd 1071 Captures Evidence of Distinctive Dinosaur Sociality. Acta Palaeontologica Polonica, 53(4), 567-

1072 578. doi:10.4202/app.2008.0402

1073

Vila, B., Sellés, A. G., \& Brusatte, S. L. (2016). Diversity and faunal changes in the latest Cretaceous dinosaur communities of southwestern Europe. Cretaceous Research, 57, 552-564.

Voorhies, M. (1969). Taphonomy and Population Dynamics of an Early Pliocene Vertebrate Fauna, Knox County, Nebraska. Laramie: University of Wyoming.

Wiman, C. (1931). Parasaurolophus tubicens n. sp. aus der kreide in New Mexico. Nova Acta Regiae Societatis Scietiarum Upsaliensis Ser IV, 7, 11.

Wosik, M., Chiba, K., Therrien, F., \& Evans, D. C. (2020). Testing size-frequency distributions as a method of ontogenetic aging: a life-history assessment of hadrosaurid dinosaurs from the Dinosaur Park Formation of Alberta, Canada, with implications for hadrosaurid paleoecology. Paleobiology, 46(3), 379-404.

Woodward, H. N., Freedman Fowler, E. A., Farlow, J. O., \& Horner, J. R. (2015). Maiasaura, a model organism for extinct vertebrate population biology: a large sample statistical assessment of growth dynamics and survivorship. Paleobiology, 41(4), 503-527.

1086

Xing, H., Mallon, J. C., \& Currie, M. L. (2017). Supplementary cranial description of the types of Edmontosaurus regalis (Ornithischia: Hadrosauridae), with comments on the phylogenetics and biogeography of Hadrosaurinae. PLoS One, 12(4), e0175253. Retrieved from https://doi.org/ 10.1371/journal.pone.0175253 
1090

1091

1092

1093

1094

1095

1096

1097

1098

1099

1100

1101

1102

1103

1104

1105

1106

Zanno, L., \& Erickson, G. (2006). Ontogeny and life history of Falcarius utahensis, a primitive therizinosauroid from the Early Cretaceous of Utah. Journal of Vertebrate Paleontology, 26(3), $143 \mathrm{~A}$.

Zhao, Q., Benton, M. J., Xu, X., \& Sander, P. M. (2014). Juvenile-only clusters and behaviour of the Early Cretaceous dinosaur Psittacosaurus. Acta Palaeontologica Polonica, 59(4), 827-834.

Zubalich, R., Capozzi, R., Fanti, F., \& Catuneanu, O. (2021). Evolution of the Western Interior Seaway in west-central Alberta (late Campanian, Canada): Implications for hydrocarbon exploration. Marine and Petroleum Geology, 124, 104779.

\section{Table Captions}

Table 1. List of humeri recovered from the Spring Creek Bonebed as seen in Figure 4.

Table 2. Inventory and categorization of bones in a complete juvenile hadrosaurid skeleton and expected vs observed proportions of Voorhies groups from the Spring Creek Bonebed. Expected proportions were adapted from a variety of sources (Varricchio 1995; Horner et al., 2004; Scherzer \& Varricchio, 2010; Bell \& Campione, 2014). Observed proportions were calculated from the number of identifiable specimens.

\section{Table 3. Comparison between lambeosaurine cranial bones founds at the Spring Creek}

Bonebed and other juvenile lambeosaurines. Morphological comparisons are based on the following specimens: Corythosaurus casuarius: ROM 759 from (Evans et al., 2005); Hypacrosaurus altispinus: CMN 2247 from (Brink et al., 2011); Hypacrosaurus stebingeri: TMP.1994.385.01, TCMI 2001.96.02, and NSM-PV 20377 from (Evans, 2010); Kazaklambia convincens: PIN2230/1 from Bell and Brink (2013); Lambeosaurus sp.: ROM 758 from (Brink et 
1113 al., 2011); Parasaurolophus sp.: RAM 14000 from (Farke et al., 2013); Velafrons coahuliensis:

1114 CPC-59 from (Gates et al., 2007).

1115 Table 4. Postcranial elements from the Spring Creek lambeosaurine scaled against

1116 elements from a complete Lambeosaurus sp. (AMNH 5340; from Farke et al., 2013) to

1117 estimate total body length.

1118 Table 5. Taphonomic observations from the Spring Creek Bonebed, including the results of 1119 Chi-squared tests on the number of prepared specimens.

Figure Captions

1122

Figure 1. Locality map of main macrofossil localities from the Grande Prairie area and the geographic extent of the Wapiti Formation. (A) Locality map of the main macrofossil localities proximate to Grande Prairie, Alberta, Canada. Numbers indicate the following localities: 1) George Robinson Bonebed (Tanke, 2004); 2) Mummified Edmontosaurus regalis skeleton (Bell et al., 2014a); 3) Red Willow hadrosaur (Bell et al., 2014b); 4) Wapiti River Pachyrhinosaurus Bonebed (Fanti et al., 2015); 5) Pipestone Creek Pachyrhinosaurus lakustai Bonebed (Currie et al., 2008b); 6) Spring Creek Bonebed (red star; this study). (B) Map illustrating the lateral extent of the Wapiti Formation (in grey) across Alberta and into eastern British Columbia.

Figure 2. Quarry map of the Spring Creek Bonebed. (A) Map of the 2018 and 2019 excavations of the Spring Creek Bonebed by the Boreal Alberta Dinosaur Project (grey: isolated specimens; white: specimens in concretions). (B) Associated dentary (UALVP 59898), partial dental battery (UALVP 59887), and predentary (UALVP 59888) from Spring Creek Bonebed. 
1135 Reconstruction based on Hypacrosaurus stebingeri (Brink et al., 2011). The $10 \mathrm{~cm}$ scale bar

1136 applies to the bones in B and the skull reconstruction. (C) A rose diagram of the recorded

1137 orientations of long bones from the Spring Creek Bonebed showing a preferential NE-SW

1138 modality, but overall high circular variance. (D) Quarry photo of bones in situ.

1139 Figure 3. Exposures at the Spring Creek Bonebed. (A) Photograph of the bank exposure at the

1140 Spring Creek Bonebed (indicated by white arrows). (B) Stratigraphic column from the Spring

1141 Creek Bonebed (sediment grains sizes: c, clay; m, mud; fs, fine sand; s, sand). Derek Larson

$1142(175 \mathrm{~cm})$ for scale.

1143

1144

1145

1146

1147

1148

1149

1150

1151

1152

1153

1154

1155

1156
Figure 4. Right (top) and left (bottom) humeri recovered from the Spring Creek Bonebed and denoting the minimum number of individuals (MNI=eight) and their consistent size.

Humeri show the typical lack of weathering and abrasion observed throughout the Spring Creek Bonebed. Additionally, humeri exhibit a variety of fracture styles and diagenetic distortion, causing the visible morphological variances. Note that letters correspond to Table 1 . Humeri denoted with an asterisk were sectioned for histological analyses.

Figure 5. Left lambeosaurine premaxilla (UALVP 60537) from the Spring Creek Bonebed.

(A) Lateral view, including life reconstruction based on Hypacrosaurus stebingeri (Brink et al., 2011). Grey region indicates the portion of the premaxilla that was preserved. (B) Dorsal view with a dashed white line indicating the perimeter of the exposed bony naris. Abbreviations: bn, bony naris; cdp, caudodorsal process; nv, nasal vestibule; om, oral margin.

Figure 6. Right lambeosaurine maxilla (UALVP 59881b) from the Spring Creek Bonebed.

(A) Lateral view, showing hypothetical reconstruction based on Hypacrosaurus sp. (MOR 553s

). The dashed white line indicates the anterior margin of the sutural surface for the jugal. Black

Peer) reviewing PDF | (2020:11:55729:1:1:NEW 22 Mar 2021) 
1157 arrows indicate the location of lateral foramina. (B) Medial view. (C) Anterodorsal view. (D)

1158 Dorsal view. (E) Anterior cross section and schematic showing three internal teeth and one

1159 erupted tooth. (F) Ventral view. Abbreviations: af, alveolar foramina; df, dorsal foramen; dp,

1160 dorsal process; ec, ectopterygoid ridge; mt, maxillary teeth; ps, premaxillary shelf; sdf,

1161 secondary dorsal foramen; ssj, sutural surface for the jugal.

1162

1163

1164

1165

1166

1167

1168

1169

1170

1171

1172

1173

1174

1175

1176

1177

1178

1179

Figure 7. Left lambeosaurine postorbital (UALVP 59902) from the Spring Creek Bonebed.

(A) Dorsolateral view. (B) Ventromedial view. White dashed line outlines the shape of the

latersphenoid fossa. Note the longitudinal fracture on the medial surface in (B), which could also represent a neurovascular canal. Abbreviations: jp, jugal process; or, orbital rim; sp, squamosal process; ssf, sutural surface for frontal; ssp, sutural surface for parietal; sspf, sutural surface for prefrontal.

Figure 8. Thin sections of Spring Creek Bonebed humeri showing bone microstructure. (A) Thin section of a humerus (UALVP 60539) showing the typical bone microstructure of humeri from the Spring Creek Bonebed, as described in the text. Scale bar $=1 \mathrm{~mm}$. White arrows: 1 , cancellous bone; 2, reticular bone; 3, plexiform bone; 4, laminar bone; 5, Haversian bone. (B) Laminar bone from UALVP 60533. Scale bar $=500 \mu \mathrm{m}$. (C) Reticular bone from UALVP 60535. Scale bar $=500 \mu \mathrm{m}$. (D) Plexiform bone from UALVP 60535. Scale bar $=500 \mu \mathrm{m}$. (E) Haversian reconstruction from UALVP 60539. Scale bar $=500 \mu \mathrm{m}$.

Figure 9. Examples of bone modification from the Spring Creek Bonebed. (A) Unhealed parallel toothmarks (white arrows) on the lateral surface of the left dentary (UALVP 59907) interpreted as post mortem scavenging. (B) Pathology (margin indicated by white arrows) on the lateral surface of the supra-acetabular process (sa) from an incomplete ilium (UALVP 60540). (C) Example of paralell striae on the diaphysis of a fibula (UALVP 59982). 
1180 Figure 10. Biostratigraphy and palaeobiogeography of temporally and spatially proximate

1181 Lambeosaurinae from Alberta, Canada, Montana, USA, and Mexico. (A) Biostratigraphic

1182 distribution of Lambeosaurinae across strata from northwestern (Fanti \& Catuneanu, 2009; this

1183 study) and southern Alberta, Canada (Mallon et al., 2012; Eberth et al., 2013; Eberth \& Kamo,

1184 2020), Montana, USA (Horner \& Currie, 1994; Campbell et al., 2019), western and northeastern

1185 Mexico (Lucas \& Sullivan, 2006; Gates et al., 2007; Prieto-Márquez et al., 2012; Fowler, 2017).

1186 The Wapiti and Horseshoe Canyon formations are subdivided into units and members,

1187 respectively. Grey strata represent marine formations. The dashed error ranges for the Spring

1188 Creek lambeosaurines represents a temporal range within Unit 3, between the Pipestone Creek

1189 Bonebed ( 73.5 Ma; Currie et al., 2008b) and the basal-most Horseshoe Canyon Formation

1190 ( 74.4 Ma; Eberth \& Braman, 2012). (B) Paleobiogeographical distribution of Lambeosaurinae

1191 across Montana, USA, Alberta, Canada, and Mexico (Lull \& Wright, 1942; Horner \& Currie,

1192 1994; Evans \& Reisz, 2007; Evans et al., 2007; Gates et al., 2007; Evans et al., 2009; Evans,

1193 2010; Prieto-Márquez et al., 2012). The silhouette of the Spring Creek lambeosaurine and

1194 Magnapaulia laticaudus were created by Scott Hartman and Dmitry Bogdanov, respectively.

1195 Both were vectorized by T. Michael Keesey and used under the creative commons attribution 3.0

1196 unported license (https://creativecommons.org/licenses/by/3.0/). The remaining silhouettes were

1197 used and modified under the public domain dedication 1.0 license. All silhouettes were sourced

1198 from www.phylopic.org.

1199 Supplementary Figure Captions

1200 Supplementary Figure 1. Additional images of humeri thin sections from the Spring Creek

1201 Bonebed. (A) UALVP 60534. (B) UALVP 60537. (C) UALVP 60536. Scale bars represent 500

$1202 \mu \mathrm{m}$.

PeerJ reviewing PDF | (2020:11:55729:1:1:NEW 22 Mar 2021) 
1203 Supplementary Figure 2. Additional images of humeri thin sections from the Spring Creek

1204 Bonebed. (A) UALVP 60533. (B) UALVP 60532. (C) TMP 1988.94.0006. (D) TMP

1205 1991.137.0009. White scale bars in (A) and (B) represent $500 \mu \mathrm{m}$.

1206 Supplementary Figure 3. Additional images of humeri thin sections from the Spring Creek

1207 Bonebed. (A) UALVP 60533. (B) UALVP 60539. (C) UALVP 60532.

1208 


\section{Table $\mathbf{1}$ (on next page)}

List of humeri recovered from the Spring Creek Bonebed as seen in Figure 4. 
1 Table 1. List of humeri recovered from the Spring Creek Bonebed as seen in Figure 4.

2 Institutional abbreviations: UoA, University of Alberta, Edmonton, Canada; UNE, University of

3 New England, Armidale, Australia.

\begin{tabular}{|c|c|c|c|c|}
\hline $\begin{array}{l}\text { Figure } \\
\text { Identifier }\end{array}$ & Specimen Number & Element & Length (mm) & $\begin{array}{l}\text { Sectioning } \\
\text { Institution }\end{array}$ \\
\hline $\bar{A}$ & TMP 1991.137.0005 & $\begin{array}{l}\text { Right humerus } \\
\text { (proximal) }\end{array}$ & $282^{*}$ & \\
\hline B & UALVP 60537 & Right humerus & 261 & UoA \\
\hline $\mathrm{C}$ & UALVP 60539 & Right humerus & 247 & UoA \\
\hline $\mathrm{D}$ & UALVP 60534 & Right humerus & $246^{* *}$ & UoA \\
\hline $\mathrm{E}$ & UALVP 60536 & Right humerus & $262 * *$ & UoA \\
\hline $\mathrm{F}$ & UALVP 60532 & Right humerus (distal) & $268^{*}$ & UoA \\
\hline G & UALVP 60535 & $\begin{array}{l}\text { Right humerus } \\
\text { (proximal) }\end{array}$ & $252 *$ & \\
\hline $\mathrm{H}$ & UALVP 60541 & $\begin{array}{l}\text { Right humerus } \\
\text { (proximal) }\end{array}$ & $270^{*}$ & \\
\hline I & TMP 1991.127.0001 & Left humerus & 253 & \\
\hline $\mathrm{J}$ & UALVP 60533 & Left humerus (distal) & $231^{*}$ & UoA \\
\hline $\mathrm{K}$ & TMP 1991.137.0009 & Left humerus (distal) & $279^{*}$ & UNE \\
\hline $\mathrm{L}$ & TMP 1988.94.0002 & Left humerus (distal) & $235^{*}$ & \\
\hline \multirow[t]{2}{*}{$\mathrm{M}$} & TMP 1988.94.0006 & Left humerus (distal) & $254^{*}$ & UNE \\
\hline & Humerus length: & Mean $=257 \mathrm{~mm}$ & $\mathrm{sd}=15.5 \mathrm{~mm}$ & \\
\hline
\end{tabular}

4 *Estimated lengths

$5 \quad * *$ Have undergone diagenetic modification 


\section{Table 2 (on next page)}

Inventory and categorization of bones in a complete juvenile hadrosaurid skeleton and expected vs observed proportions of Voorhies groups from the Spring Creek Bonebed.

Expected proportions were adapted from a variety of sources (Varricchio 1995; Horner et al., 2004; Scherzer \& Varricchio, 2010; Bell \& Campione, 2014). Observed proportions were calculated from the number of identifiable specimens. 
1 Table 2. Inventory and categorization of bones in a complete juvenile hadrosaurid skeleton

2 and expected vs observed proportions of Voorhies groups from the Spring Creek Bonebed.

3 Expected proportions were adapted from a variety of sources (Varricchio 1995; Horner et al.,

4 2004; Scherzer \& Varricchio, 2010; Bell \& Campione, 2014). Observed proportions were

5 calculated from the number of identifiable specimens.

\begin{tabular}{|c|c|c|c|c|c|c|c|c|}
\hline \multicolumn{2}{|l|}{ Voorhies Group I } & \multicolumn{3}{|c|}{ Voorhies Group II } & \multicolumn{3}{|c|}{ Voorhies Group III } & \multirow[b]{2}{*}{ Count } \\
\hline Category & Element & Count & Category & Element & Count & Category & Element & \\
\hline \multirow[t]{13}{*}{$\begin{array}{l}\text { Light cranial } \\
\text { elements }\end{array}$} & Premaxillae & 2 & Pectoral elements & $\begin{array}{l}\text { Sternal } \\
\text { plates }\end{array}$ & 2 & Limb bones & Humeri & 2 \\
\hline & Nasals & 2 & & Coracoids & 2 & & Radii & 2 \\
\hline & Lacrimals & 2 & & Scapulae & 2 & & Ulnae & 2 \\
\hline & Jugals & 2 & $\begin{array}{l}\text { Dense cranial } \\
\text { elements }\end{array}$ & Maxillae & 2 & & Femora & 2 \\
\hline & Quadratojugals & 2 & & Dentaries & 2 & & Tibiae & 2 \\
\hline & Postorbitals & 2 & & Braincase & 1 & & Fibulae & 2 \\
\hline & Surangulars & 2 & $\begin{array}{l}\text { Tarsals and } \\
\text { metapodials }\end{array}$ & Astragali & 2 & & & \\
\hline & Exoccipitals & 2 & & Metatarsals & 6 & & & \\
\hline & Hyoids & 2 & & Metacarpals & 6 & & & \\
\hline & Squamosals & 2 & & & & & & \\
\hline & Quadrates & 2 & & & & & & \\
\hline & Frontals & 2 & & & & & & \\
\hline & Ectopterygoids & 2 & & & & & & \\
\hline \multirow[t]{2}{*}{ Digital elements } & Pedal phalanges & 24 & & & & & & \\
\hline & $\begin{array}{l}\text { Manual } \\
\text { phalanges }\end{array}$ & 24 & & & & & & \\
\hline Ribs & Dorsal ribs & 36 & & & & & & \\
\hline \multirow{4}{*}{$\begin{array}{l}\text { Vertebrae } \\
\text { (including isolated } \\
\text { centra) }\end{array}$} & Cervical & 13 & & & & & & \\
\hline & Dorsal & 18 & & & & & & \\
\hline & Caudal & 50 & & & & & & \\
\hline & Sacral & 9 & & & & & & \\
\hline \multirow[t]{5}{*}{$\begin{array}{l}\text { Vertebral } \\
\text { processes }\end{array}$} & $\begin{array}{l}\text { Transverse } \\
\text { processes }\end{array}$ & 84 & & & & & & \\
\hline & Neural spines & 49 & & & & & & \\
\hline & Haemal arches & 35 & & & & & & \\
\hline & $\begin{array}{l}\text { Expected } \\
\text { proportion }\end{array}$ & $89.6 \%$ & \multicolumn{2}{|c|}{ Expected proportion } & $7.5 \%$ & \multicolumn{2}{|c|}{ Expected proportion } & $2.9 \%$ \\
\hline & Observed proportion & $48 \%$ & \multicolumn{2}{|c|}{ Observed proportion } & $23.3 \%$ & \multicolumn{2}{|c|}{ Observed proportion } & $28.7 \%$ \\
\hline $\begin{array}{r}\text { Chi-squared } \\
\text { results: }\end{array}$ & $\begin{array}{l}\text { X-squared }=41.746 \\
\mathrm{df}=2 \\
\mathrm{p} \text {-value }<<0.001\end{array}$ & & & & & & & \\
\hline
\end{tabular}




\section{Table 3 (on next page)}

Comparison between lambeosaurine cranial bones founds at the Spring Creek Bonebed and other juvenile lambeosaurines.

Morphological comparisons are based on the following specimens: Corythosaurus casuarius:

ROM 759 from (Evans et al., 2005); Hypacrosaurus altispinus: CMN 2247 from (Brink et al., 2011); Hypacrosaurus stebingeri: TMP.1994.385.01, TCMI 2001.96.02, and NSM-PV 20377 from (Evans, 2010); Kazaklambia convincens: PIN2230/1 from Bell and Brink (2013); Lambeosaurus sp.: ROM 758 from (Brink et al., 2011); Parasaurolophus sp.: RAM 14000 from (Farke et al., 2013); Velafrons coahuliensis: CPC-59 from (Gates et al., 2007). 
1 Table 3. Comparison between lambeosaurine cranial bones founds at the Spring Creek

2 Bonebed and other juvenile lambeosaurines. Morphological comparisons are based on the

3 following specimens: Corythosaurus casuarius: ROM 759 from (Evans et al., 2005);

4 Hypacrosaurus altispinus: CMN 2247 from (Brink et al., 2011); Hypacrosaurus stebingeri:

5 TMP.1994.385.01, TCMI 2001.96.02, and NSM-PV 20377 from (Evans, 2010); Kazaklambia

6 convincens: PIN2230/1 from Bell and Brink (2013); Lambeosaurus sp.: ROM 758 from (Brink et

7 al., 2011); Parasaurolophus sp.: RAM 14000 from (Farke et al., 2013); Velafrons coahuliensis:

8 CPC-59 from (Gates et al., 2007).

\begin{tabular}{|c|c|c|c|c|c|c|c|}
\hline $\begin{array}{l}\text { Spring Creek } \\
\text { Lambeosaurine } \\
\text { Morphologies } \\
\end{array}$ & 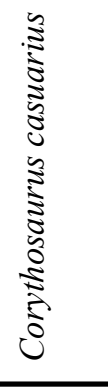 & 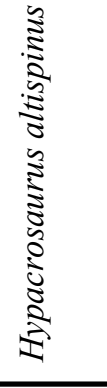 & 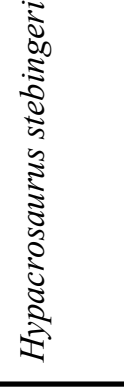 & 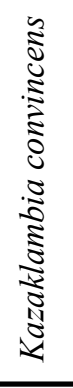 & 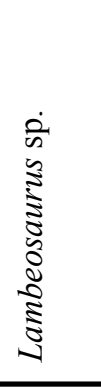 & 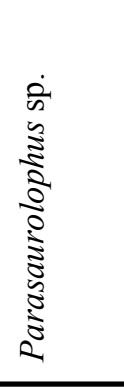 & 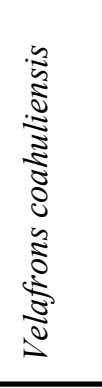 \\
\hline \multicolumn{8}{|l|}{ Premaxilla } \\
\hline $\begin{array}{l}\text { No ventrolateral tab- } \\
\text { like process }\end{array}$ & NA & No & No & NA & Yes & No & No \\
\hline $\begin{array}{l}\text { Bony naris attenuates } \\
\text { anterior to crest snout } \\
\text { angle }\end{array}$ & No & Yes & No & NA & Yes & NA & Yes \\
\hline $\begin{array}{l}\text { Crest-snout angle } \\
\sim 158^{\circ}\end{array}$ & $\sim 155^{\circ}$ & $\sim 169^{\circ}$ & $\sim 150^{\circ} *$ & NA & $\sim 156^{\circ}$ & $\sim 162^{\circ *}$ & $\sim 157^{\circ}$ \\
\hline \multicolumn{8}{|l|}{ Maxilla } \\
\hline $\begin{array}{l}\text { Dorsal opening } \\
\text { foramen }\end{array}$ & NA & Yes & NA & NA & NA & NA & Yes \\
\hline $\begin{array}{l}\text { Secondary dorsal } \\
\text { foramen }\end{array}$ & Yes & NA & NA & NA & NA & NA & NA \\
\hline $\begin{array}{l}\text { Anterodorsal angle } \\
\sim 151^{\circ}\end{array}$ & $\sim 149^{\circ}$ & $\sim 147^{\circ}$ & $\sim 143^{\circ *}$ & NA & $\sim 154^{\circ}$ & $\sim 165^{\circ} *$ & $\sim 144^{\circ}$ \\
\hline \multicolumn{8}{|l|}{ Postorbital } \\
\hline $\begin{array}{l}\text { No prefrontal contact } \\
\text { doming }\end{array}$ & Yes & Yes & Yes & No & Yes & Yes & Yes \\
\hline
\end{tabular}




\begin{tabular}{|c|c|c|c|c|c|c|c|}
\hline $\begin{array}{l}\text { Arcuate antorbital } \\
\text { fenestra margin }\end{array}$ & Yes & No & Yes & No & No & No & No \\
\hline $\begin{array}{l}\text { Bifurcated squamosal } \\
\text { process }\end{array}$ & Yes & No & Yes & Yes & Yes & Yes & Yes \\
\hline
\end{tabular}

10

*Measured from reconstructions 


\section{Table 4(on next page)}

Postcranial elements from the Spring Creek lambeosaurine scaled against elements from a complete Lambeosaurus sp. (AMNH 5340; from Farke et al., 2013) to estimate total body length. 
1 Table 4. Postcranial elements from the Spring Creek lambeosaurine scaled against

2 elements from a complete Lambeosaurus sp. (AMNH 5340; from Farke et al., 2013) to

3 estimate maximum total body length.

\begin{tabular}{lclc}
\hline Taxon & $\begin{array}{c}\text { Lambeosaurus } \\
\text { sp. (Farke et al., } \\
\text { 2013) }\end{array}$ & $\begin{array}{c}\text { Lambeosaurinae indet. (this } \\
\text { study) }\end{array}$ & $\begin{array}{c}\text { Ratio of Spring Creek } \\
\text { Specimens to AMNH } \\
5340\end{array}$ \\
\hline Specimen & AMNH 5340 & $\begin{array}{l}\text { Longest Spring Creek } \\
\text { specimens } \\
\text { 261 UALVP 60537 }\end{array}$ & 0.86 \\
Humerus length (mm) & 305 & 558 BADP 2019.0813.03** & 0.94 \\
Femur length (mm) & 590 & 547 TMP.1995.024.0002 & 0.99 \\
Tibia length (mm) & 550 & 455 TMP.1991.137.17 & 0.86 \\
Fibula length $(\mathrm{mm})$ & 530 & $5.27 *$ & \\
Total Length $(\mathbf{m})$ & 4.31 & & \\
\hline
\end{tabular}

4

5 Brackets indicate scale factor from AMNH 5340

$6 \quad *$ Estimated body length

$7 \quad * *$ Based on field measurements of unprepared specimens 


\section{Table 5 (on next page)}

Taphonomic observations from the Spring Creek Bonebed, including the results of Chisquared tests on the number of prepared specimens. 
1 Table 5. Taphonomic observations from the Spring Creek Bonebed, including the results of Chi-squared tests on the number of prepared

2 specimens.

\begin{tabular}{|c|c|c|c|c|c|}
\hline $\begin{array}{l}\text { Weathering Stage } \\
\text { (Behrensmeyer, 1978; Fiorillo, } \\
\text { 1988) }\end{array}$ & $\begin{array}{l}\text { Observed } \\
\text { proportion }\end{array}$ & $\begin{array}{l}\text { Abrasion Stage } \\
\text { (Fiorillo, 1988) }\end{array}$ & $\begin{array}{l}\text { Observed } \\
\text { proportion }\end{array}$ & Fracture Style & $\begin{array}{l}\text { Observed } \\
\text { proportion }\end{array}$ \\
\hline $\begin{array}{l}\text { Stage 0: No signs of cracking } \\
\text { or flaking on bone. } \\
\text { Possible years exposed after } \\
\text { death: } 0-1\end{array}$ & $72.9 \%$ & $\begin{array}{l}\text { Stage 0: Bone is unabraded, } \\
\text { preserving all processes and } \\
\text { edges. }\end{array}$ & $84.3 \%$ & $\begin{array}{l}\text { Complete: Bone is } \\
\text { preserved in its entirety. }\end{array}$ & $44.2 \%$ \\
\hline $\begin{array}{l}\text { Stage 1: Bone is beginning to } \\
\text { show signs of longitudinal } \\
\text { cracking. } \\
\text { Possible years exposed after } \\
\text { death: } 0-3\end{array}$ & $16.8 \%$ & $\begin{array}{l}\text { Stage 1: Slight abrasion with } \\
\text { some rounding of edges. }\end{array}$ & $13.9 \%$ & $\begin{array}{l}\text { Spiral: Fractures with } \\
\text { irregular fracture } \\
\text { surfaces preserved from } \\
\text { pre-burial. }\end{array}$ & $7.6 \%$ \\
\hline $\begin{array}{l}\text { Stage 2: Thin layers of bone } \\
\text { flaking, typically associated } \\
\text { with longitudinal cracks. } \\
\text { Possible years exposed after } \\
\text { death: } 2-6\end{array}$ & $10.3 \%$ & $\begin{array}{l}\text { Stage 2: Moderate abrasion } \\
\text { in which edges are well- } \\
\text { rounded, and processes may } \\
\text { or may not be identifiable. }\end{array}$ & $0.9 \%$ & $\begin{array}{l}\text { Transverse: Straight, } \\
\text { transverse fractures } \\
\text { preserved from post } \\
\text { burial. }\end{array}$ & $9.3 \%$ \\
\hline $\begin{array}{l}\text { Stage 3: Patches of exposed } \\
\text { fibrous texture where } \\
\text { concentrically layered bone has } \\
\text { been removed. } \\
\text { Possible years exposed after } \\
\text { death: } 4-15+\end{array}$ & $0 \%$ & $\begin{array}{l}\text { Stage 3: High level of } \\
\text { abrasion, edges extremely } \\
\text { rounded, original bone shape } \\
\text { is barely recognisable. }\end{array}$ & $0.9 \%$ & $\begin{array}{l}\text { Mixed: Both transverse } \\
\text { and spiral fractures } \\
\text { preserved. }\end{array}$ & $38.9 \%$ \\
\hline \multicolumn{2}{|c|}{$\begin{aligned} \text { Chi-squared results: } & X^{2}=71.08 \\
& p \text {-value }<<0.001\end{aligned}$} & \multicolumn{2}{|c|}{$\begin{aligned} \text { Chi-squared results: } X^{2}=191.77 \\
\text { p-value }<<0.001\end{aligned}$} & \multicolumn{2}{|c|}{$\begin{aligned} \text { Chi-squared results: } X^{2}=44.538 \\
\text { p-value }<<0.001\end{aligned}$} \\
\hline
\end{tabular}

3 
Figure 1

Locality map of main macrofossil localities from the Grande Prairie area and the geographic extent of the Wapiti Formation.

(A) Locality map of the main macrofossil localities proximate to Grande Prairie, Alberta, Canada. Numbers indicate the following localities: 1) George Robinson Bonebed (Tanke, 2004); 2) Mummified Edmontosaurus regalis skeleton (Bell et al., 2014a); 3) Red Willow hadrosaur (Bell et al., 2014b); 4) Wapiti River Pachyrhinosaurus Bonebed (Fanti et al., 2015); 5) Pipestone Creek Pachyrhinosaurus lakustai Bonebed (Currie et al., 2008b); 6) Spring Creek Bonebed (red star; this study). (B) Map illustrating the lateral extent of the Wapiti Formation (in grey) across Alberta and into eastern British Columbia.

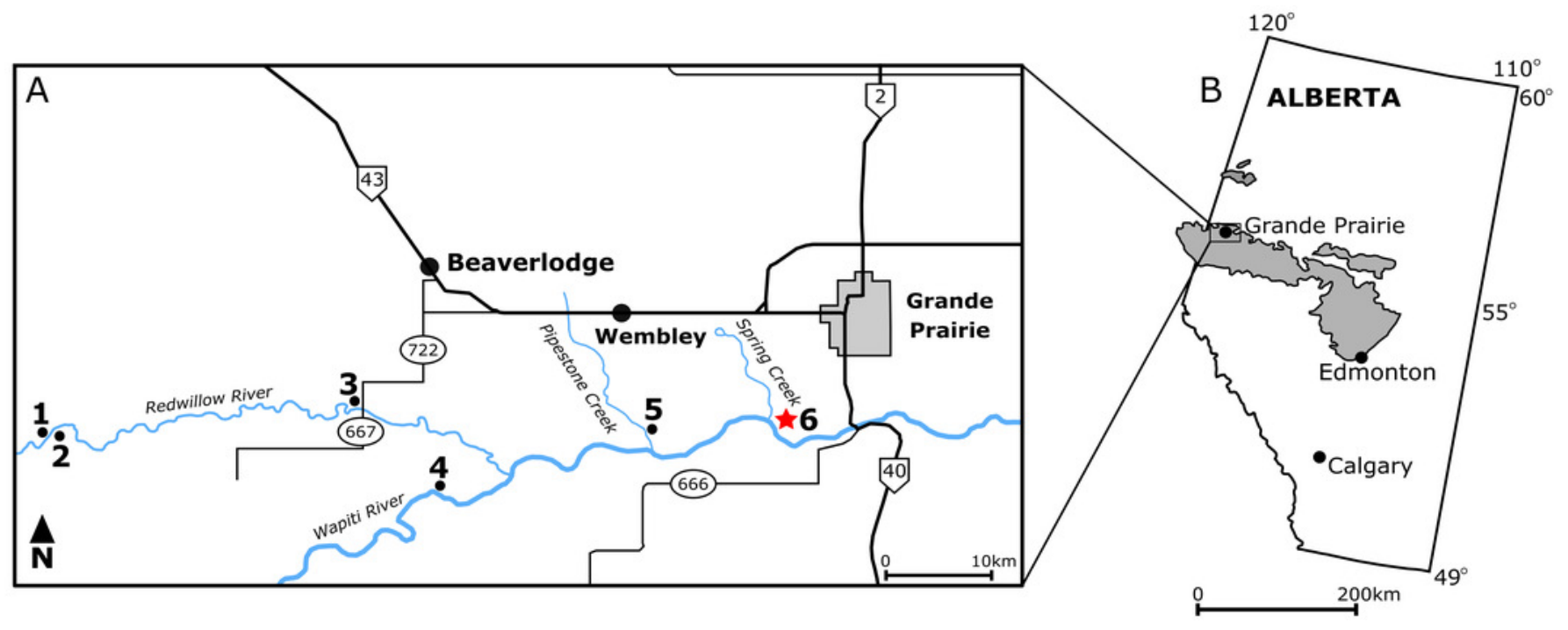




\section{Figure 2}

Quarry map of the Spring Creek Bonebed.

(A) Map of the 2018 and 2019 excavations of the Spring Creek Bonebed by the Boreal Alberta Dinosaur Project (grey: isolated specimens; white: specimens in concretions). (B) Associated dentary (UALVP 59898), partial dental battery (UALVP 59887), and predentary (UALVP 59888) from Spring Creek Bonebed. Reconstruction based on Hypacrosaurus stebingeri (Brink et al., 2011). The $10 \mathrm{~cm}$ scale bar applies to the bones in B and the skull reconstruction. (C) A rose diagram of the recorded orientations of long bones from the Spring Creek Bonebed showing a preferential NE-SW modality, but overall high circular variance. (D) Quarry photo of bones in situ. 


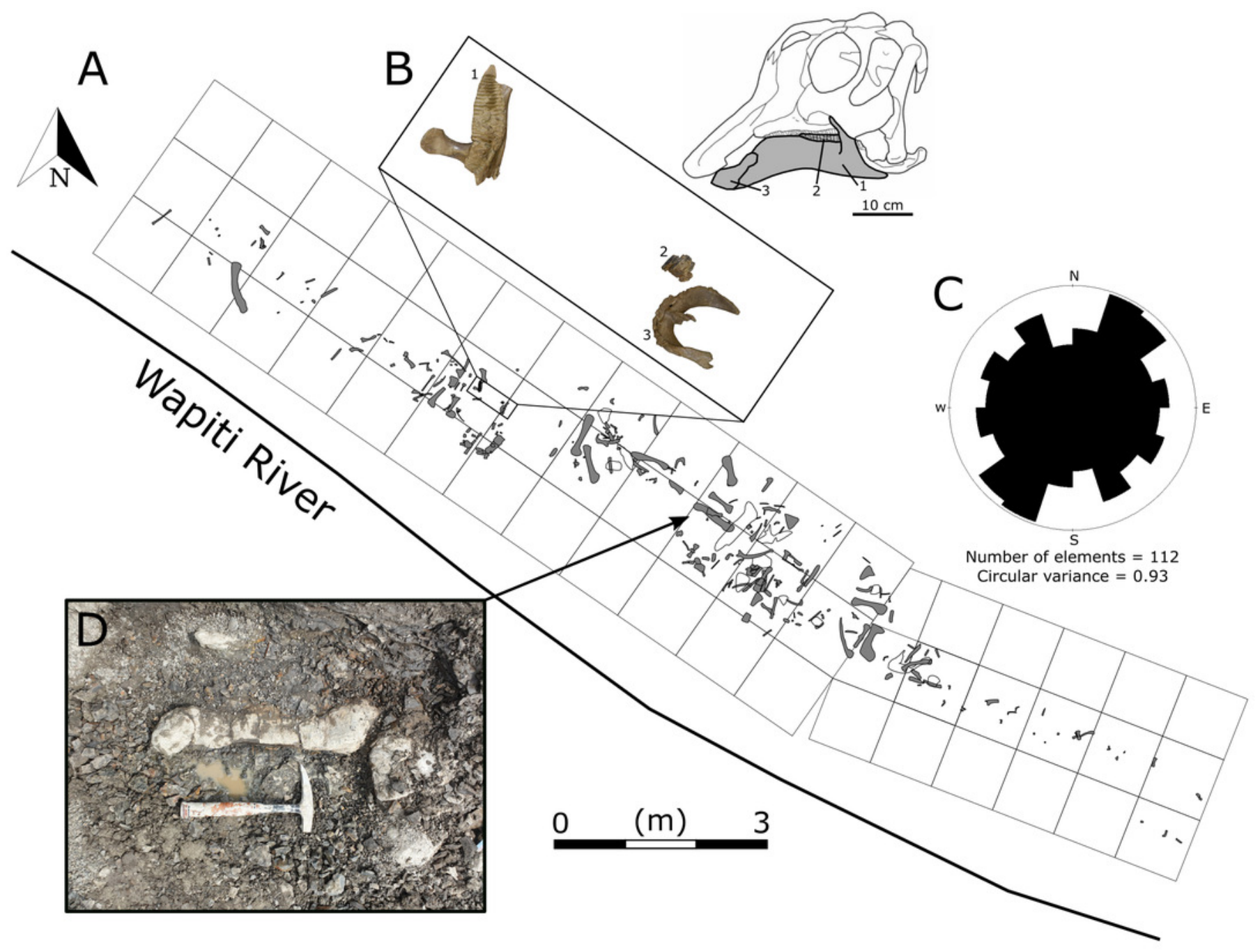




\section{Figure 3}

Exposures at the Spring Creek Bonebed.

(A) Photograph of the bank exposure at the Spring Creek Bonebed (indicated by white arrows). (B) Stratigraphic column from the Spring Creek Bonebed (sediment grains sizes: C, clay; m, mud; fs, fine sand; s, sand). Derek Larson $(175 \mathrm{~cm})$ for scale.
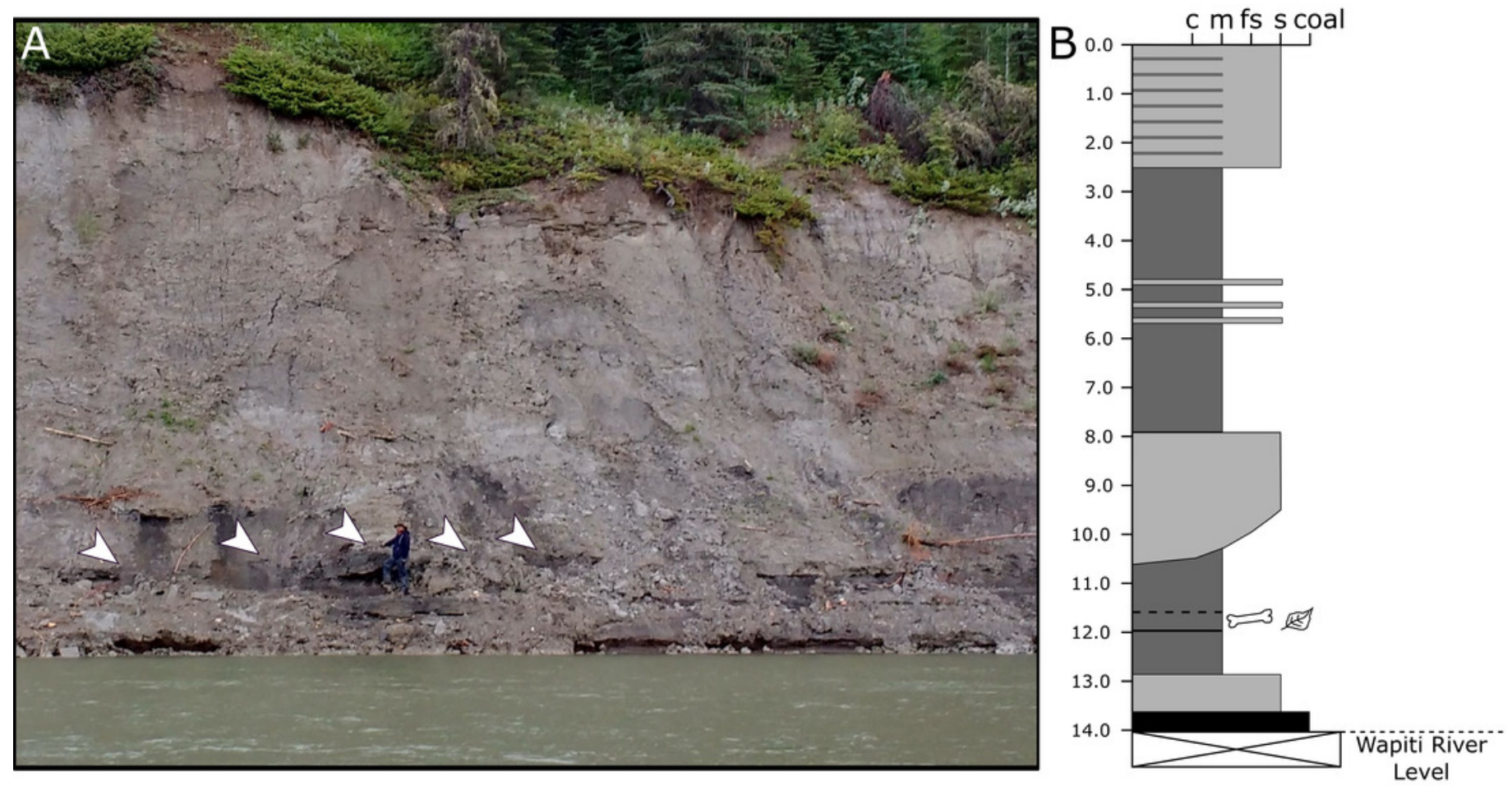


\section{Figure 4}

Right (top) and left (bottom) humeri recovered from the Spring Creek Bonebed and denoting the minimum number of individuals ( $\mathrm{MNI}=$ eight) and their consistent size.

Humeri show the typical lack of weathering and abrasion observed throughout the Spring Creek Bonebed. Additionally, humeri exhibit a variety of fracture styles and diagenetic distortion, causing the visible morphological variances. Note that letters correspond to Table 1. Humeri denoted with an asterisk were sectioned for histological analyses. 

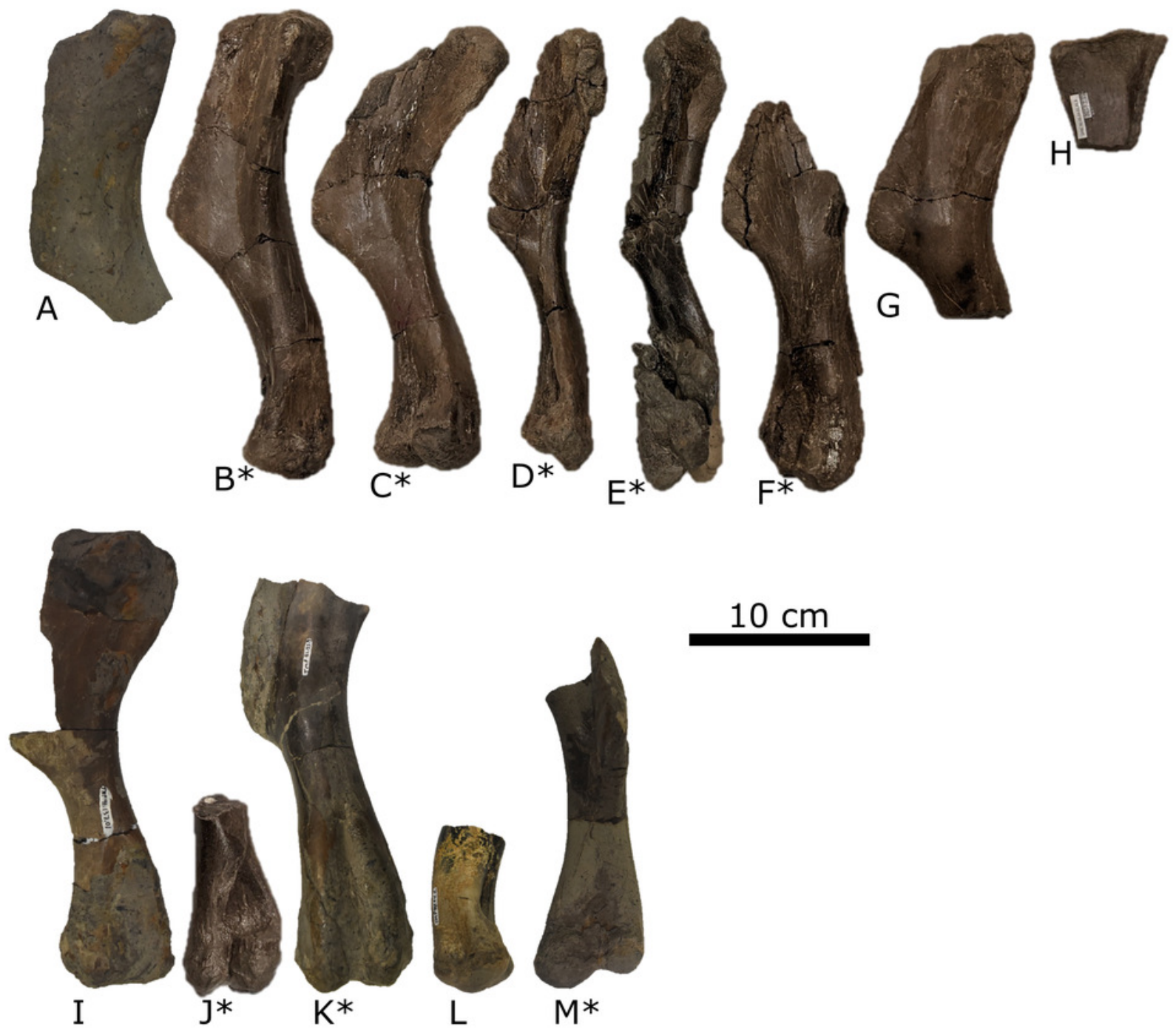


\section{Figure 5}

Left lambeosaurine premaxilla (UALVP 60537) from the Spring Creek Bonebed.

(A) Lateral view, including life reconstruction based on Hypacrosaurus stebingeri (Brink et al., 2011). Grey region indicates the portion of the premaxilla that was preserved. (B) Dorsal view with a dashed white line indicating the perimeter of the exposed bony naris. Abbreviations: bn, bony naris; cdp, caudodorsal process; nv, nasal vestibule; om, oral margin.

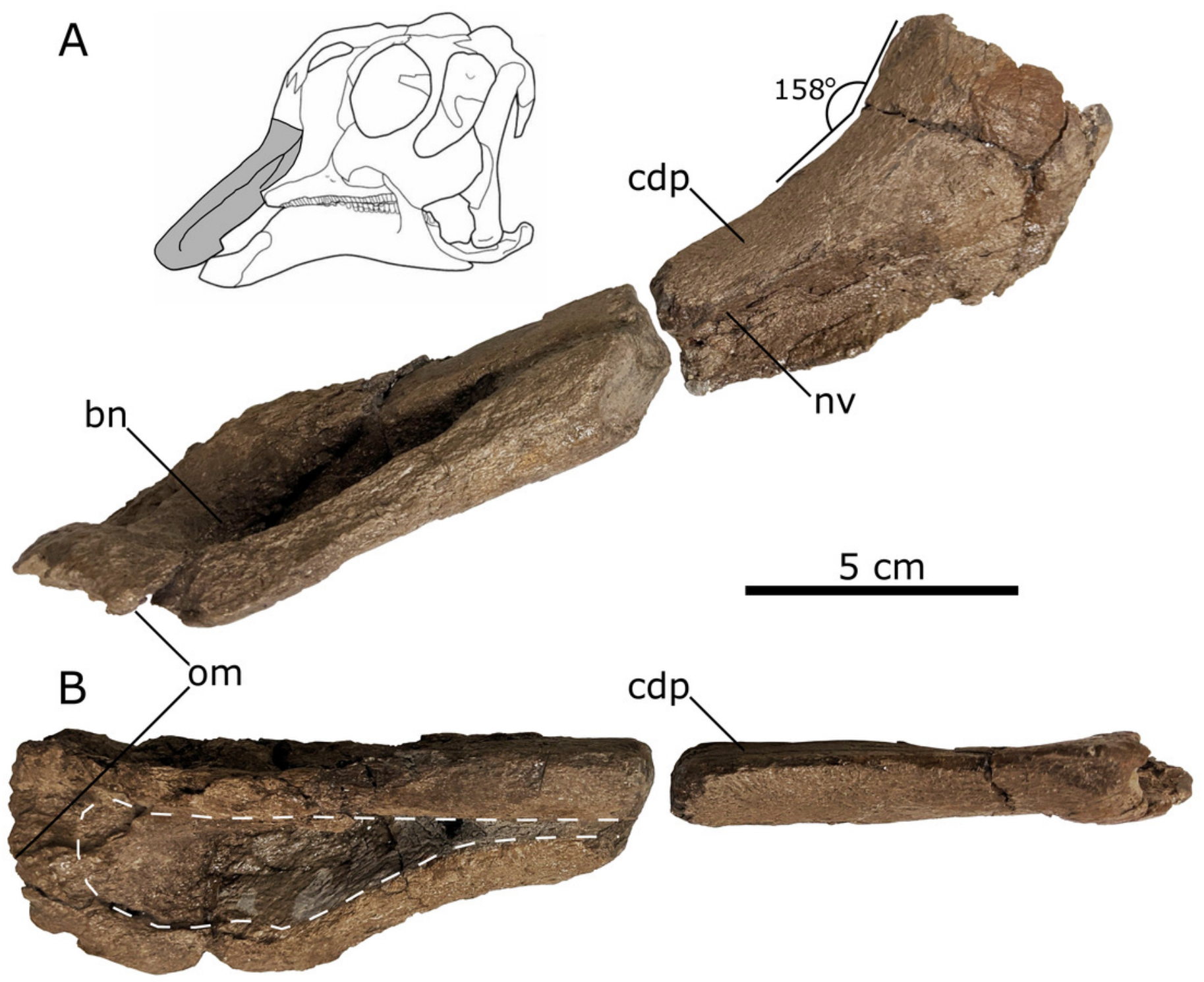




\section{Figure 6}

Right lambeosaurine maxilla (UALVP 59881b) from the Spring Creek Bonebed.

(A) Lateral view, showing hypothetical reconstruction based on Hypacrosaurus sp. (MOR 553s

). The dashed white line indicates the anterior margin of the sutural surface for the jugal.

Black arrows indicate the location of lateral foramina. (B) Medial view. (C) Anterodorsal view.

(D) Dorsal view. (E) Anterior cross section and schematic showing three internal teeth and one erupted tooth. (F) Ventral view. Abbreviations: af, alveolar foramina; df, dorsal foramen; $\mathrm{dp}$, dorsal process; ec, ectopterygoid ridge; $\mathrm{mt}$, maxillary teeth; ps, premaxillary shelf; sdf, secondary dorsal foramen; ssj, sutural surface for the jugal. 


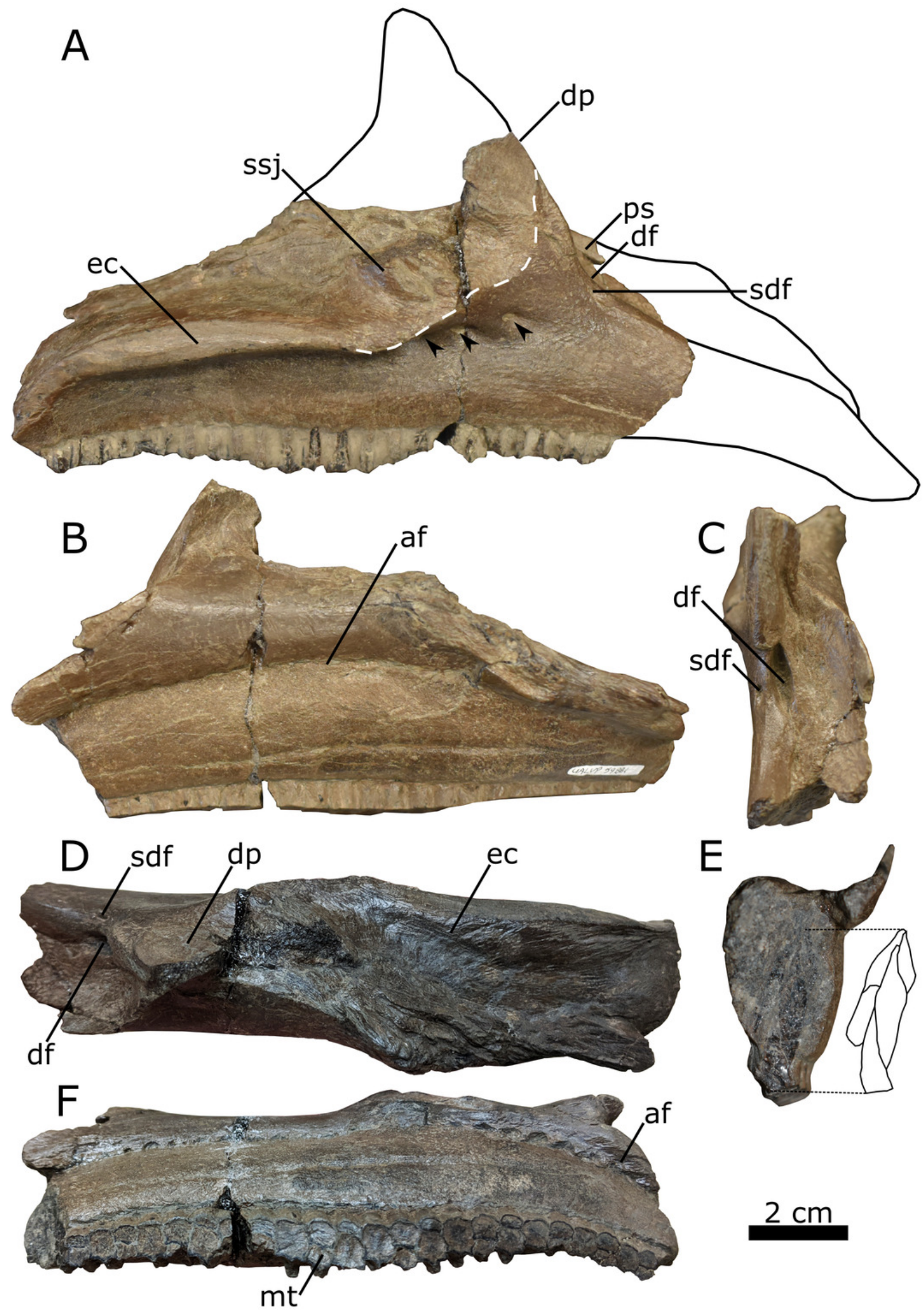

Peer] reviewing PDF | (2020:11:55729:1:1:NEW 22 Mar 2021) 


\section{Figure 7}

Left lambeosaurine postorbital (UALVP 59902) from the Spring Creek Bonebed.

(A) Dorsolateral view. (B) Ventromedial view. White dashed line outlines the shape of the latersphenoid fossa. Note the longitudinal fracture on the medial surface in (B), which could also represent a neurovascular canal. Abbreviations: jp, jugal process; or, orbital rim; sp, squamosal process; ssf, sutural surface for frontal; ssp, sutural surface for parietal; sspf, sutural surface for prefrontal.

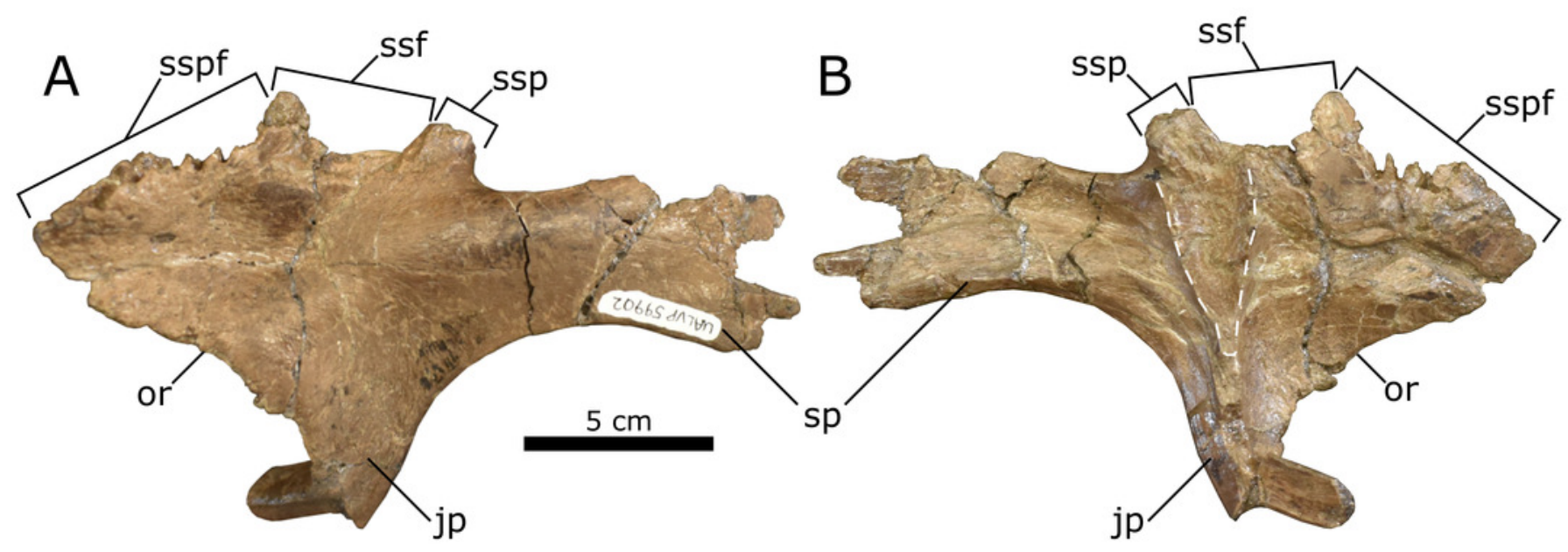




\section{Figure 8}

Thin sections of Spring Creek Bonebed humeri showing bone microstructure.

<!--[if !msEquation]--> <!--[if !vml]--> <!--[endif]--><!--[endif]--> (A) Thin section of a humerus (UALVP 60539) showing the typical bone microstructure of humeri from the Spring Creek Bonebed, as described in the text. Scale bar $=1 \mathrm{~mm}$. White arrows: 1 , cancellous bone; 2, reticular bone; 3, plexiform bone; 4, laminar bone; 5 , Haversian bone. (B) Laminar bone from UALVP 60533. Scale bar $=500 \mu \mathrm{m}$. (C) Reticular bone from UALVP 60535. Scale bar $=500 \mu \mathrm{m}$. (D) Plexiform bone from UALVP 60535. Scale bar $=500 \mu \mathrm{m}$. (E) Haversian reconstruction from UALVP 60539. Scale bar $=500 \mu \mathrm{m}$. 

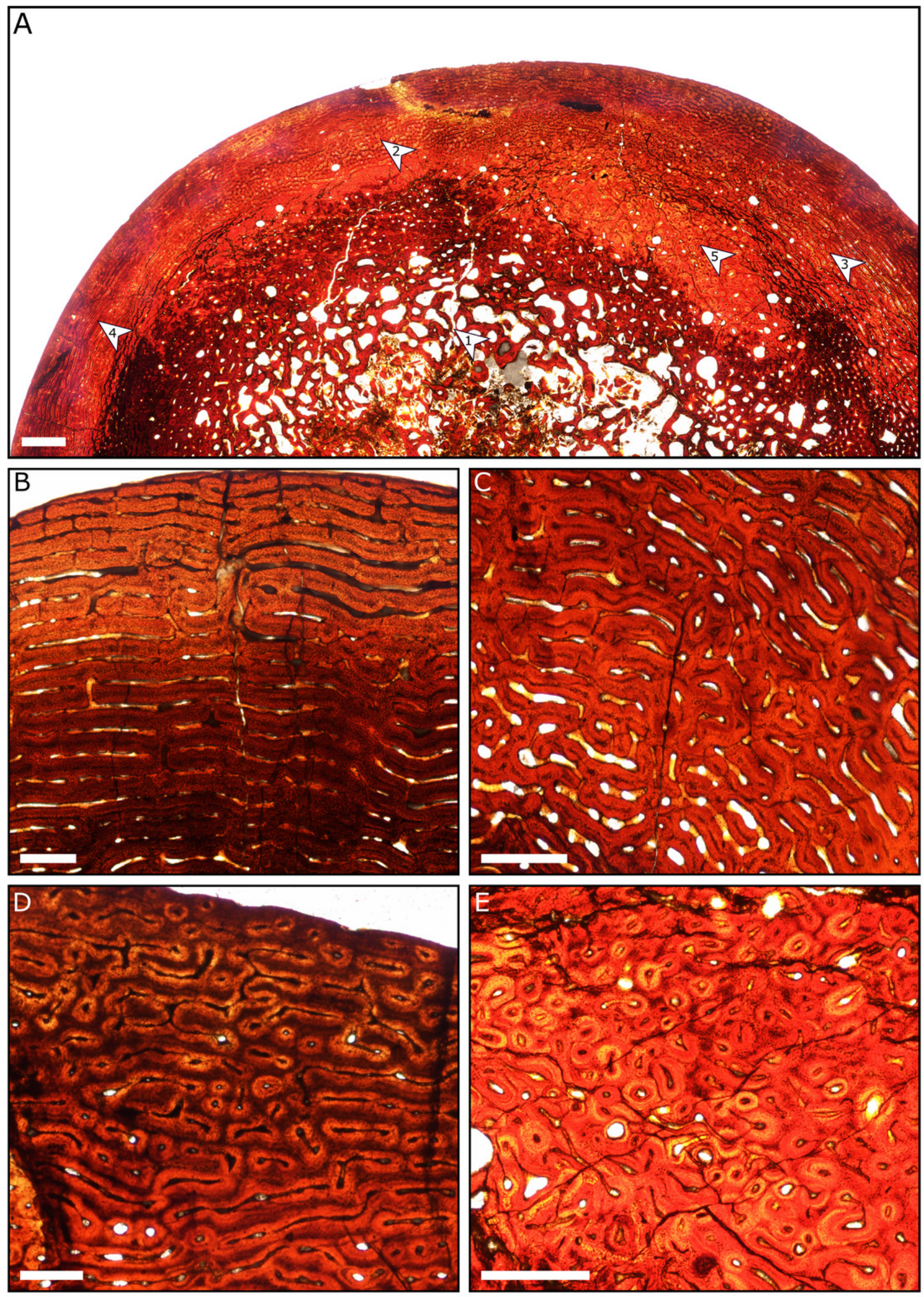


\section{Figure 9}

Examples of bone modification from the Spring Creek Bonebed.

(A) Unhealed parallel toothmarks (white arrows) on the lateral surface of the left dentary (UALVP 59907) interpreted as post mortem scavenging. (B) Pathology (margin indicated by white arrows) on the lateral surface of the supra-acetabular process (sa) from an incomplete ilium (UALVP 60540). (C) Example of paralell striae on the diaphysis of a fibula (UALVP 59982).

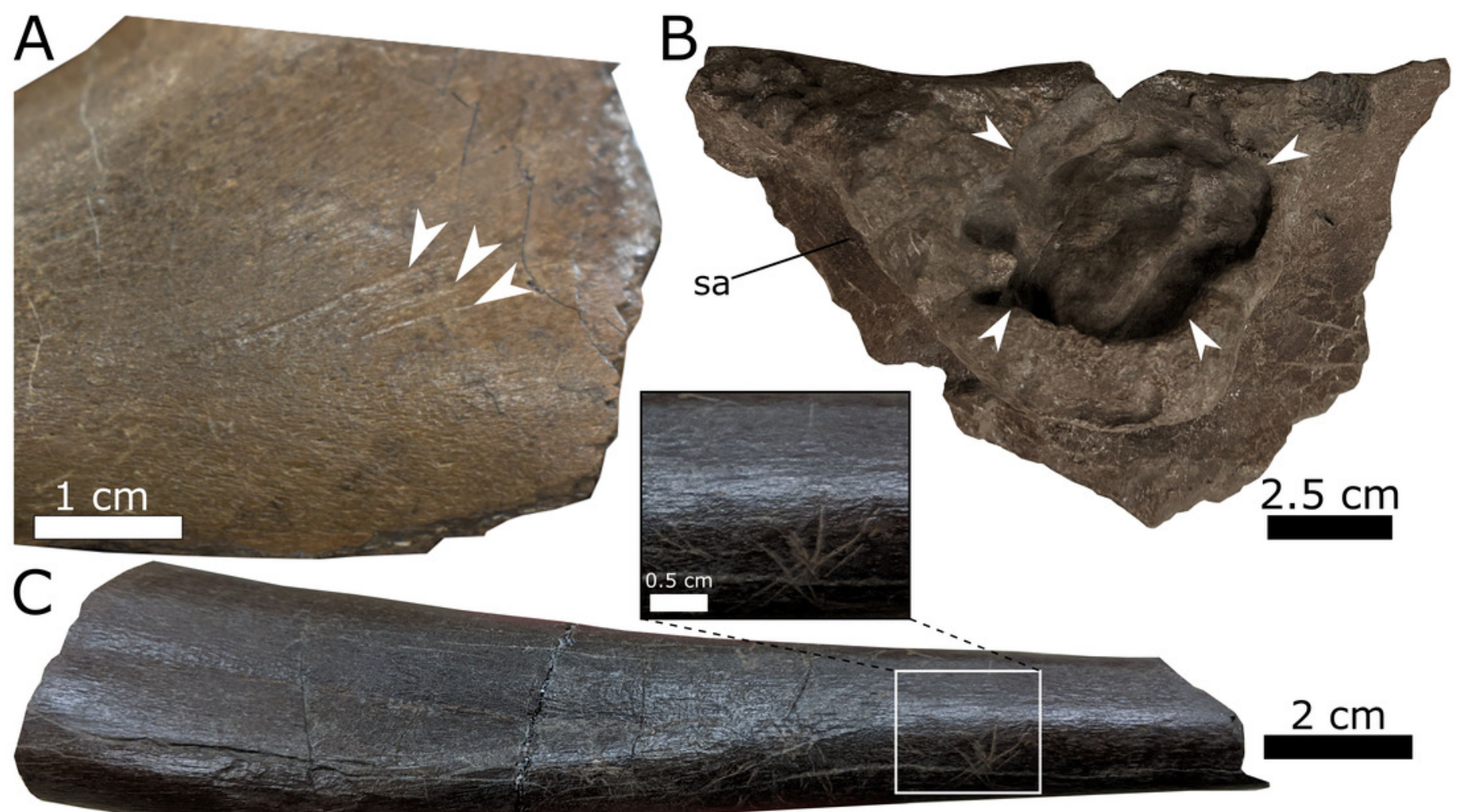




\section{Figure 10}

Biostratigraphy and palaeobiogeography of temporally and spatially proximate Lambeosaurinae from Alberta, Canada, Montana, USA, and Mexico.

(A) Biostratigraphic distribution of Lambeosaurinae across strata from northwestern (Fanti \& Catuneanu, 2009; this study) and southern Alberta, Canada (Mallon et al., 2012; Eberth et al., 2013; Eberth \& Kamo, 2020), Montana, USA (Horner \& Currie, 1994; Campbell et al., 2019), western and northeastern Mexico (Lucas \& Sullivan, 2006; Gates et al., 2007; Prieto-Márquez et al., 2012; Fowler, 2017). The Wapiti and Horseshoe Canyon formations are subdivided into units and members, respectively. Grey strata represent marine formations. The dashed error ranges for the Spring Creek lambeosaurines represents a temporal range within Unit 3, between the Pipestone Creek Bonebed ( 73.5 Ma; Currie et al., 2008b) and the basal-most Horseshoe Canyon Formation ( 74.4 Ma; Eberth \& Braman, 2012). (B) Paleobiogeographical distribution of Lambeosaurinae across Montana, USA, Alberta, Canada, and Mexico (Lull \& Wright, 1942; Horner \& Currie, 1994; Evans \& Reisz, 2007; Evans et al., 2007; Gates et al., 2007; Evans et al., 2009; Evans, 2010; Prieto-Márquez et al., 2012). The silhouette of the Spring Creek lambeosaurine and Magnapaulia laticaudus were created by Scott Hartman and Dmitry Bogdanov, respectively. Both were vectorized by T. Michael Keesey and used under the creative commons attribution 3.0 unported license ( https://creativecommons.org/licenses/by/3.0/ ). The remaining silhouettes were used and modified under the public domain dedication 1.0 license. All silhouettes were sourced from www. phylopic.org . 


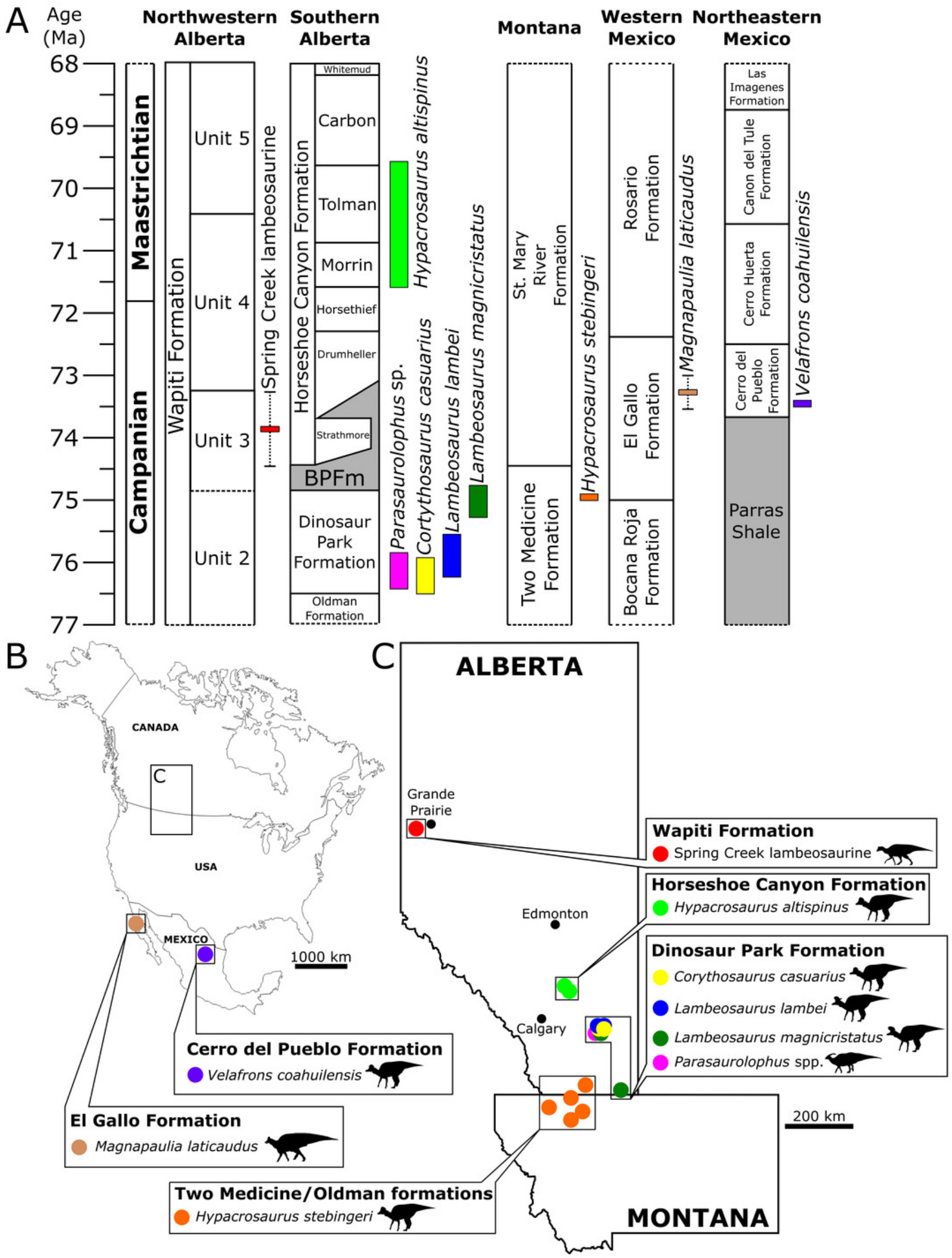

